\title{
La serpiente en las monedas. Transmisión iconográfica de una antigua creencia
}

\author{
ANA M." VAzQuez HoYs *
}

Aunque parezca algo excepcional, tal vez por los diferentes objetivos que ambas actividades parecen perseguir, hay veces, a menudo más de las que el historiador imagina, en las que economía y religión van unidas.

Ya hemos defendido esta tesis otras veces, a propósito del poder económico de los templos semitas ${ }^{1}$ y hemos visto cómo muchas veces, a lo largo de la historia, las monedas han sido utilizadas no sólo como instrumento económico sino también como vehículo de propagación de ideas políticas y de difusión de determinadas ideas religiosas, sirviéndose para ello de los diferentes tipos impresos en sus caras.

La importancia de las monedas como documento es obvia, como recuerda Turcan. Y a menudo, grandes historiadores en el campo de la Historia de las Religiones, como A. Alföldy y el mismo Turcan, han con-

* Departamento de Historia Antigua. UNED.

Vazouez Hors, A. M." "Lixus en el panorama religioso fenicio de Occidente", Actes du colloque organise par l'Institut des Sciences de l'archéologie et du patrimoine de Rabat, avec le concours de lÉcole trançaise de Rome. Larache, 8-11 de noviembre de 1989: Roma. École Française de Rome, 1992. págs. 103-113; Idem, "El comercio entre Hispania y Mauritania y el templo de Hércules-Melkart en Gades en época de luba II y Ptolomeo". " Congreso El Estrecho de Gibraltar. Ceuta, noviembre 1990, Idem, "L'activité commercial du temple tyrien de Melkart et son expansion maritime: Un possible precedent biblique", Xth. International Colloquium "Phoenicia and the Bible. Archaeology, History, Epigraphy". Leuven, Groupe de Contacts Interuniversitaires d'études phéniciennes et puniques, Katholieque Universiteit, febrero de 1900; Idem. "Los oráculos y su "poder". El sueño de Jacob. el poder oracular de Heracles y el "sueño" de César: ¿Empresas comerciales?". Homenaje a J. M." Blázquez. Madrid Departamento de Historia Antigua, Universidad Complutense, 1990, en prensa; Idem, «Perduración y cambio de significado de la serpiente en las monedas antiguas", "Congreso de Arys. Jarandilla de la Vera, Cáceres, diciembre de 1990, en prensa; Idem, "El templo de Heracles-Melkart y su papel económico", Revista de Studis Economics. Palma de Mallorca, en prensa. 
tribuido a la difusión de esta idea con notables estudios sobre el tema que ahora nos ocupa ${ }^{2}$.

Es por ello y puesto que damos por supuesto el valor propagandístico político y religioso de las monedas, por lo que queremos referirnos en este trabajo a algunas representaciones monetales de la serpiente, tratando de averiguar su posible significado y el valor que pudo tener su imagen como reflejo de unas determinadas ideas religiosas. Pero, ante todo, dejando bien entendida la dificultad del tema, ya que los tipos numismáticos varían con el tiempo, a veces de un reino a otro o de una emisión a otra y cada emisión requiere un tratamiento apropiado, en conjunción con la coyuntura histórica o política que la origina, pero siempre en función de las tradiciones monetarias. $E$ incluso hay que recordar, también, que, a veces, la figura de una divinidad, en una moneda, puede no tener un significado religioso, como ocurre, por ejemplo, en las series acuñadas por Galieno en Colonia en el año 258-259. En ellas, según Turcan, los dioses Vulcano, Marte y Segetia transcriben una intención política en cuanto que se dirigen a ciertos medios profesionales o categorías sociales descontentas (artesanos, soldados, campesinos), cuya actividad era vital para la Galia del noroeste, ya que, como recuerda dicho autor, al menos en época romana, las monedas eran un instrumento de propaganda que, al circular de mano en mano, era vehículo de los slogans que el poder emisor quería difundir ${ }^{3}$.

Pero en nuestros ejemplos no nos limitaremos solamente a la época romana, sino que veremos la posible significación de la serpiente en algunas monedas griegas, que, emitidas sobre todo en época helenística, aún perduran durante el Imperio romano.

Se trata de los cistóforos, monedas llamadas así porque llevaban en el anverso la cista mística, propia del culto a Dioniso, de la que escapaba una serpiente (fig. 1). Estas monedas, cuyas emisiones llegan hasta bien avanzada la época imperial romana, dejan de emitirse con el tipo de la serpiente cuando parece perderse el significado religioso y simbólico de este animal dentro de las religiones paganas.

Después examinaremos cómo persiste y se transmite cronológicamente el tipo de la serpiente en las monedas de diversas ciudades griegas en

ALFOLDY, A, "Die Kontorniaten, ein verkanntes Propagandamittes der stadrmischen heid. nischen Aristokratie in inrem Kampie gegen das christliche Kaisertum". Festchrif der hungar numismatichen Gesel/schtft. Budapest 1943. Idem, ALFOLDY, E., Die Kontorniat-Medaillons. Berlín 1976; TuRCAN, R., Numismatique romaine de culte metroaque. Leiden, Ed. Brill, 1983, Introduction.

TURCAN, OP. cit, Introductión. 


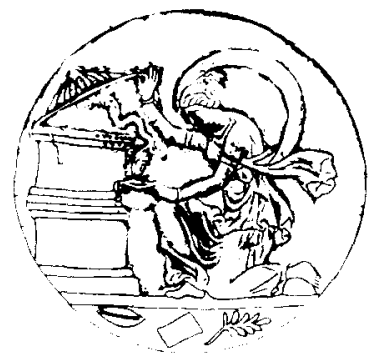

Fig. 1. Serpiente saliendo de una cista mistica, a la que una menade da de beber. KELLER, O.. Die Antike Tierwelt. Leipzig 1913, fig. 105.

relación con las diferentes divinidades con las que está unidas, iconográfica y culturalmente.

Finalmente, veremos la perduración del tipo de la serpiente en las emisiones cristianas, como imagen de los enemigos de la Iglesia, ya en los siglos IV-V d.C., y expresión de las ideas imperiales cristianas en lucha contra los herejes.

Nuestro propósito es demostrar la pervivencia de un tipo numismático desde la Grecia clásica y helenistica (figs. 2-6) hasta fines del Imperio romano, deteniéndonos en momentos puntuales y determinados, ya que el estudio exhaustivo de todas las emisiones en las que está representado este animal excede los limites de este trabajo.

La significación del tipo iconográfico, aunque muy parecida, parece ser, sin embargo, diferente, según la clase de serpiente que se representa, ya que la figura de este animal es muy variada e incluso cambia de forma, dependiendo de los dioses a los que acompaña o en función del significado que quiere atribuírsele. $Y$ tal vez lo más importante que apreciamos al estudiar la figura de este animal en las monedas es el cambio de significado que apreciamos de época pagana a cristiana.

En nuestra opinión, la serpiente en las monedas griegas es un genio protector, un Agathós Daimon, que significa prosperidad y riqueza y que a su carácter de divinidad protectora de los hogares y de las ciudades y Estados añade el ser una imagen habitual, conocida, que confiere a las monedas la fiabilidad casi mágica de su imagen, apotropaica y bienhechora, además del respaldo económico de los templos de las divinidades con cuya figura se emiten. Tal sería el caso de los citados cistóforos.

Para los Emperadores cristianos, en cambio, la serpiente era un animal maligno. Representaba al enemigo del Imperio, el oponente a su poder. Pero, sobre todo, era el gran vencido, politica y religiosamente. $Y$, en 


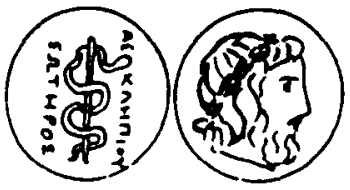

Fig. 2. Moneda de Pérgamo, Misia. 200-133 a.C. Vara de Asclepio/Cabeza de Zeus o Asclepio. PLANT, núm. 2323.

definitiva, el último reducto del paganismo, el demonio y la herejía que se oponían al cristianismo triunfante.

\section{LOS CISTÓFOROS Y OTRAS MONEDAS GRIEGAS Y ROMANAS CON SERPIENTES}

\section{a) Los cistóforos}

Los tetradracmas que llevaban el nombre de cistóforos debian esta denominación, como dijimos, a que tenían por tipo, generalmente en su anverso, la cista mística, emblema esencial de los misterios dionisíacos, que está entreabierta y deja escapar una serpiente (fig. 8), rodeada en algunas monedas de una corona de hiedra provista de corimbos. En la otra cara, los cistóforos llevaban gorytós (arco en su carcaj) entre dos serpientes cuyas colas se entrelazaban, con las cabezas levantadas. El didracma (o demicistóforo) y el dracma llevaban la leonté o piel del león de Nemea, con la clava de Hércules en el anverso, rodeada de una corona de pámpanos y el racimo de uvas en el reverso. También existían en la serie de los cistóforos trióbolos o hemidracmas (fig. 6), en los que se representaba la cista rodeada de una corona de pámpanos en el anverso $y$ en el reverso un ramo de uvas con sus hojas ${ }^{4}$.

La amplia difusión de los cistóforos queda demostrada por los variados lugares en los que se emitieron, aunque siempre dentro del marco del

Sobre este tema de las monedas ctr. MARION, D.. "Le thême de la grappe de raisin dans la numismatique antique", Cahiers Numismatiques 26, 1970, págs. 101-111. En general sobre los cistóforos cfr. Lenormant, Fr., en Daremberg-Saglio 1213-13, s.v. cistophori; KLEINER, F. S., "The Dated Cistophori of Ephesus", Mus. Notes Amer. Num. Society 18. 1972. págs. 17 y ss. NOE. S. P., "Beginnings of the cistophoric coinage", Mus. Notes Amer. Num. Society 4, 1950 págs. 29 y sS: ROBinSON, G., "Cistophori in the name of King Eumenes". Num. Chron. VI, 14. 1954, pag. 1: NEwELL, E. T., The Pergamene mint under Philetaerus. Nueva York 1936. WesteR MARK. U.. Das bildnis des Philatairos von Pergamon. Estocolmo 1960; KLAINER, G., "Bildnis und Gestaalt des Mithridates", Jahrbuch 68, 1953. págs. 73 y SS: Fernandez Uriel. P., Vazouez Hoys. A. M." y cit. en nota 47 , infra 


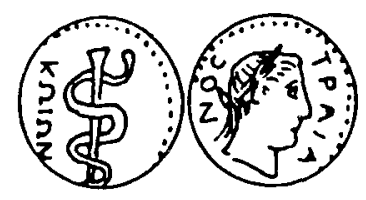

Fig. 3. Moneda de Cos, Caria. 98-117 d.C. Vara de Asclepio/Cabeza de Trajano. PLANT, núm. 2326.

Mediterráneo oriental y más concretamente en el área de Asia Menor y el Egeo oriental (mapa 1). No sólo se acuñaron en las grandes ciudades como Efeso, Pérgamo y Esmirna, sino también en ciudades más pequeñas, de provincias alejadas de Pérgamo, como Caria, Ponto, Paflagonia y algunas de Creta. Estas ciudades tuvieron sus propias cecas y acuñaron sus propias monedas de piata. Los diferentes autores no están de acuerdo a la hora de señalar las ciudades en que se acuñaron estas monedas. Para la mayoría estos lugares fueron:

- En Misia: Las ciudades de Pario, Adramitio y Pérgamo.

- En Jonia: Las ciudades de Esmirna y Éfeso.

- En Lidia: Las ciudades de Tiatira, Sardes y Tralles.

- En Frigia: Las ciudades de Apamea y Laodicea.

- Nisa, en las fronteras de Caria ${ }^{5}$.

En general, todas éstas son ciudades comprendidas en el dominio de los antiguos reyes de Pérgamo.

Según Schmidt ${ }^{6}$, se añadirían a éstas las ciudades de Sinada, ApoIonia, Estratonicea y Focea. Pero también conocemos en el Ponto, según Plant, acuñaciones de cistóforos en Amiso, en Fenicia en la ciudad de Sidón, y también en la Eólide, en la Troade así como en Paflagonia y en la isla de Creta ${ }^{\text {? }}$.

El significado religioso de los cistóforos queda patente en las estampaciones monetarias de sus caras. Además de la citada cista mística y la serpiente, ciertas emisiones de cistóforos representaban en sus anversos a diferentes divinidades: la cabeza de Dioniso joven, en Amiso y Sidón; en las monedas emitidas por Lidia la cabeza de Deméter rodeada de sus

Sg. Pinder, en Lenohimant. 1212. num. 7.

SCHMid, M. C. P. en RE S.v Kistophoren XI, 1. col. 524-525

PLANT. OP. Cit. 


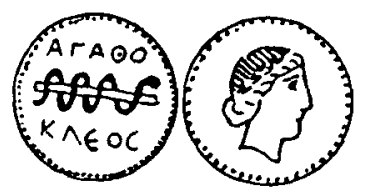

Fig. 4. Moneda de Dirracacio, lliria. 229-100 a.C. Vara de Asclepio/Cabeza de Apolo. PLANT, núm. 2324.

atributos: espiga y adormidera o simplemente se encuentran los atributos y simbolos de estas divinidades: espigas, racimos de uvas, la clava de Hércules, etc.

Mención especial, por su indudable significación, merecen las primeras emisiones de los cistóforos de Efeso ${ }^{8}$, que nos proporcionan algunas de las representaciones más antiguas de Artemis, la diosa protectora de la ciudad. En algunas emisiones, la figura de la diosa ocupa toda la superficie del anverso, cen sus característicos "polos" y "epeldites" y sus emblemas. En el reverso aparece la cista mística rodeada de dos serpientes entrelazadas.

En otras emisiones, el busto de Artemis se encuentra a la derecha de la cista mística.

Los contactos culturales, religiosos y comerciales entre el Próximo Oriente y el área Egeo oriental existían al menos desde el Bronce Antiguo ${ }^{9}$ y continuaban sin interrupción en época helenística, cuando la política económica de los reinos seleúcida y atálida llegó a afectar profundamente al mercado del mundo mediterráneo oriental.

Las primeras emisiones de los cistóforos se produjeron ante la fabricación de tetradracmas autónomos por las ciudades de Misia, Etolia y Jonia y tras las paces de Magnesia (189 a.C.) y Apamea (188 a.C.) entre Roma y Antíoco III, con la aparición de una nueva situación económica en el Egeo y la interrupción de las series dinásticas de plata.

Esto provocó la necesidad de reforzar la unidad monetaria para mantener las buenas relaciones comerciales en el mundo griego oriental. Tras esta citada paz de Apamea, Pérgamo se convirtió en el estado más poderoso de Anatolia. Ello debió decidir a sus reyes a promocionar unas

FLEICHER, T. Artemis von Ephesos und kultstatuen aus Anatolien und Sirien. Leiden 1973 págs. $38-41$ y taf. $50-53$.

Povato Holgado. C. y Vazoue? Hovs. A. M.". Introducción a la Arqueología ***. "IMilenio en el Proximo Oriente. Madrid. Ed Ramon Areces 1989. págs 551-618. 


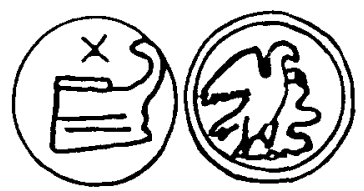

Fig. 5. Moneda de Calcis, Eubea. 196-146 a.C. Proa de nave/Aguila con serpiente. PLANT, núm. 2283.

nuevas monedas, mencionadas frecuentemente por las fuentes helenísticas e incluidas por los numísmatas entre las piezas de plata de Asia Menor. Son los llamados "cistóforos", acuñados por algunas ciudades de Asia Menor, monedas no emitidas por el monarca sino por cecas ciudadanas que, aunque comprendidas en el dominio real de Pérgamo 0 , al menos dentro de su área de influencia política y económica, eran diferentes de las cecas que emitían moneda dinástica atálida ${ }^{10}$.

Según $\mathrm{Cl}$. Préaux " esta acuñación tenía como fin ser la moneda de plata internacional de Asia Menor y al menos fue la moneda de mayor circulación durante un tiempo en esta región.
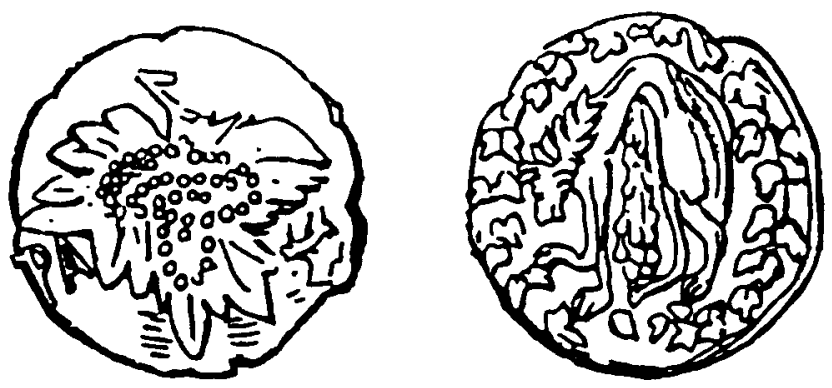

Fig. 6. Medio cistóforo acuñado en Tralles.

Pámpano de vid/Piel del león de Nemea.

Contribuyó a su expansión, sin duda, la caida de Rodas en el año 167 a.C. Según Robert ${ }^{12}$, Rodas estaría en la cumbre de su poder económico en torno al año 175 a.C., decayendo en torno al 168, tras las reformas

Sobre los Atálidas de Pérgamo cfr. VAzQuez Hors, A. M. ${ }^{\circ}$. El mundo griego desde el siglo iv Madrid. Cuadernos UNED 118, 1993, págs. 543-563.

Preaux. Cl. Le monde hellénistique. La Gréce et l'Orient (323-145 a.C.). PUF, Ed. Nouvelle Clio, 1978, t. I, págs. 291 y ss.

Robert. L.. ən Etudes de Numismatique Grecque 1951, pags. 143 y 55 


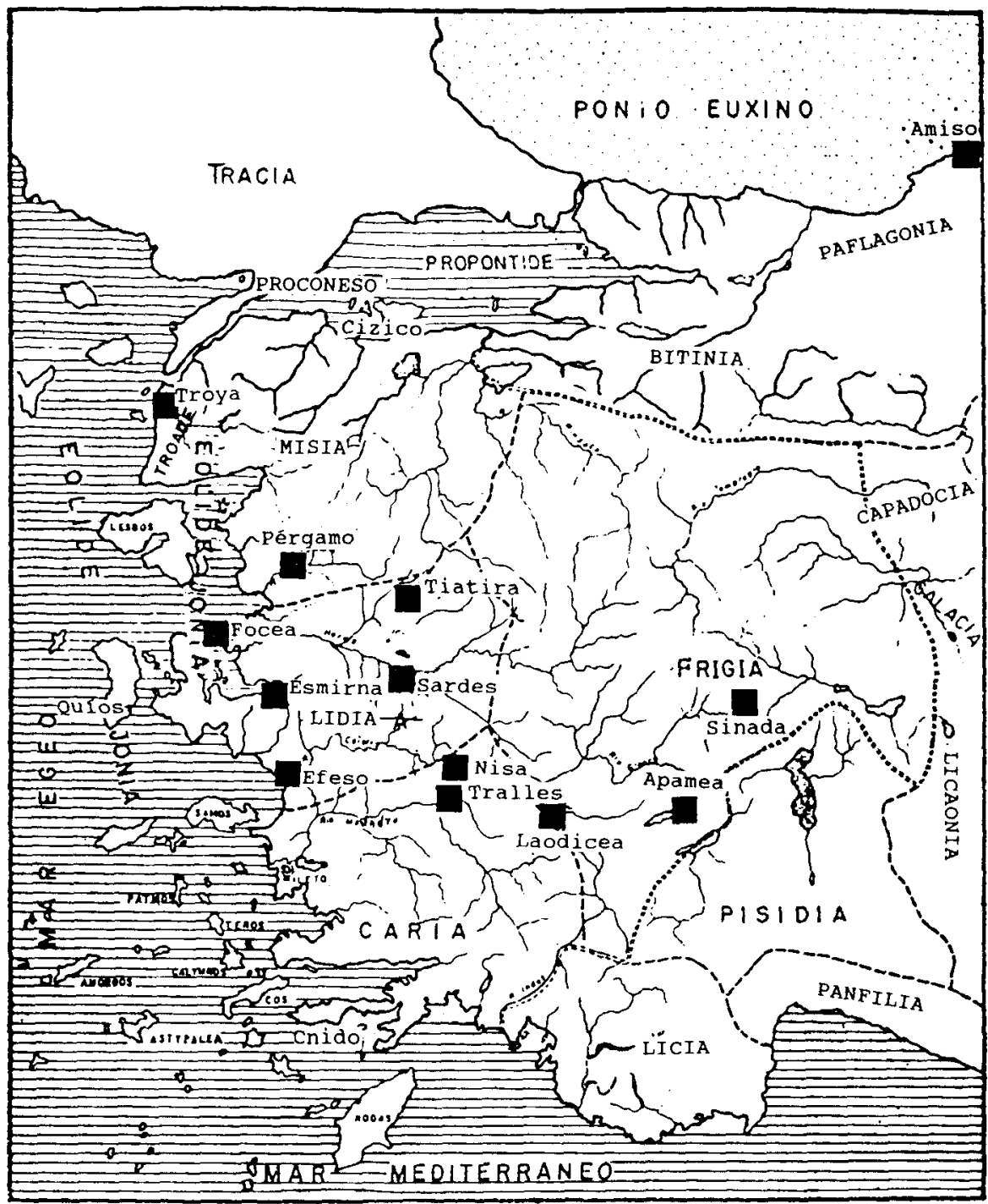

Mapa num. 1 Principales centros de emision de cistotoros en Asla Menor. 
económicas que siguieron a la batalla de Pidna. Sabemos por Polibio las preocupaciones rodias por la sanción a su estado por parte de Roma ${ }^{13}$ :

"El pueblo rodio ha perdido sus ingresos, su libertad de expresión, la igualdad politica, ideales por los que ha estado dispuesto a sufrir cualquier cosa."

Sin embargo, los origenes y los motivos que impulsaron la creación del cistóforo son objeto aún en nuestros días de una polémica por parte de los diferentes historiadores del mundo helenístico.

Para Barclay Head ${ }^{14}$, la caída de Rodas y el brusco declive de su comercio que se ocasionó a partir de entonces, inspiraron a Eumenes II de Pérgamo la idea de suplantar la moneda rodia que circulaba en Asia Menor por otra nueva, una especie de "moneda panasiática» basada en el patrón monetal rodio, acuñada en las principales ciudades bajo su mando.

En esta moneda, los diferentes lugares de emisión estaban señalados por marcas accesorias, como en el monetal contemporáneo de la Liga Aquea. Esta empresa estaría alentada por Roma que intentaba entonces arruinar el comercio rodio, erigiendo Delos como puerto franco bajo la administración de Atenas, reabriendo las minas de plata de Macedonia, por lo que los inicios de su circulación se encontrarian entre los años 160-150 a.C.

Para N. F. Parise, estas emisiones surgieron como respuesta a la introducción de la plata stephanephoros, es decir, la acuñación ateniense llamada "estilo nuevo", anteriormente datada en el año 196 a.C. ${ }^{15}$, cuya difusión estaba favorecida por la creación del puerto franco de Delos. Todo ello encajaría con el nuevo equilibrio establecido tras la batalla de Pidna.

Estas opiniones sobre la cronología inicial de los cistóforos son aún dudosas. Los numísmatas opinan que las emisiones más antiguas de los cistóforos podrían datarse en torno al año 200 a.C. y aún antes, iniciándose las acuñaciones quizás en Pérgamo, aunque también se encuentran emisiones antiguas en Esmirna y Ełeso ${ }^{16}$.

${ }^{13}$ Cfr. POLIBIO XXX, 4 sobre las preocupaciones rodias; sobre la sanción a Rodas por parte romana id. $X X X, 31$

" BaRCLAY HEAD, M., On the chronological sequence of the coins of Ephesus, pág. 61.

is PARISE, N. F., "Las emisiones monetarias helenísticas", en BANDINELLI, B. (ed.), Historia y civilización de los griegos. Barcelona 1977, t. VIII, pág. 105

i6 KLEINER, F. S., "The Late cistophori of Apameia", en Morkholm, Otto y Waggonner, Nancy M. (eds.), Greek Numismatics and Archaeology. Essays in Honor of Margaret Thompson. Bélgica. Wetteren, 1979, págs. 119-130 
Para Lenormant, la más antigua mención de estas monedas hecha por los autores antiguos se remonta a la guerra de Roma contra Antioco el Grande de Siria. a principios del siglo $\|$ a.C., cuando los cistóforos constituian la mayor parte del numerario que circulaba en Asia Menor y en algunas partes de Grecia. Se citan gran cantidad de cistóforos en los botines obtenidos por diversos generales romanos ${ }^{17}$. Así, en el triunto de Manio Acilio Glabrio sobre Antioco y la Liga Etolia ${ }^{18}$, en el 190 a.C.: en el de L. Aemilio Regillo en su victoria sobre la flota del rey de Siria ${ }^{19}$ y también en la de L. Cornelio Scipio Asiagenes después de su victoria definitiva, en el año 188 a.C. ${ }^{20}$. Dos años después, cuando Cn. Manlio Vulso recibió el triunfo tras su campaña contra los gálatas y expuso el botín de su armada, había, entre otras monedas, 25.000 cistóforos ${ }^{21}$.

Para Momsem ${ }^{2}$ estas cifras dadas por Livio son una conversión al sistema de los cistóforos, en lugar de tratarse de estas monedas y los cistóforos sólo comenzaron a emitirse tras la creación de la provincia romana de Asia, posiblemente para facilitar la circulación monetaria en dicha provincia.

La razón decisiva para la creación de los cistóforos, para Welles, pudo haber sido no el deseo de no herir los sentimientos de los Seleúcidas, ofreciéndoles como suplemento a su moneda la propia moneda de los Atálidas, sino crear para sus necesidades una especie de moneda internacional, "neutral» e impersonal.

Puede añadirse a esto, según Rostovtzeff, el hecho de que ellos adoptaron el mismo sistema en ésta época respecto a los cistóforos. Otros gobernantes, principalmente Antioco IV y los reyes macedónios, actuaron de forma similar respecto a varias ciudades de sus reinos. Es imposible decir si esto se hizo con el fin de extender el riesgo de la nueva aventura y si los reyes sacaban algún provecho sustancial de las operaciones de acuñación de las ciudades, pero al menos estas emisiones dan testimonio de la participación de las pequeñas y grandes ciudades de Asia Menor en la prosperidad del reino pergameneo.

PLANT, R. Greek coin types and their identification. Londres 1979. pag. 116.

LIVIO XXVII, 46

LIVIO XXVII, 58

Livio XXXVII, 59. Cfr. PINDER, M., "Uber die Cistophoren und uber die kaiserlichen Silbermedaillons der romischen Provinz. Asia", Abh. Berlin 1885, págs. 533.635.

LIVIO XXXIX. 7.

MOMSEM. Th. Histoire de la monnaie romaine. t. III, pág. 806. 
Indudablemente, todas las ciudades que acuñaban cistóforos de plata en sus propias cecas no podian tener suficiente metal para lograr emitir una moneda buena y respetada fácilmente en el mercado.

Es de suponer que los reyes atálidas, dueños de importantes minas de plata, fueran quienes suministrasen el metal para estas acuñaciones, para dar salida a esta plata y contribuir a sostener un sistema monetario uniforme que facilitara el comercio, sin herir susceptibilidades en la política internacional, en especial a los monarcas seleúcidas, ofreciendo como suplemento a la moneda acuñada por estos reyes otra moneda que, aunque dirigida y financiada por los monarcas atálidas, no era su moneda "real" sino que aparecía como neutral e internacional ${ }^{23}$, sobre todo si tenemos en cuenta que los cistóforos, siguiendo en cierto modo algunas tradiciones griegas, fueron emitidos bajo la advocación de diferentes divinidades: Artemis, Deméter y Dioniso y sobre todo, de la serpiente, animal con el que también están relacionadas estas tres divinidades. $Y$, en opinión de Lenormant, por estos tipos acunados en las monedas, la emisión de los cistóforos se hizo por influencia de las grandes corporaciones semi-religiosas, semi-teatrales y politicas llamadas Dionysiaikoi Technitai.

Según $\mathrm{Cl}$. Préaux y Hansen ${ }^{24}$, se conocen dos importantes cofradias en el reino de Pérgamo: los Philetairoi de Tespies ${ }^{25}$ y los Atalistai de Teos ${ }^{26}$. Al menos éstos últimos, no son militares sino actores, technitai, de Dioniso ${ }^{27}$. La relación de éstos actores con los reyes se explica, según Préaux, porque en las fiestas reales se llamaba a estos artistas. Pero las conexiones de los Atálidas con Dioniso y sus technitai han de ser entendidas también por el interés mutuo por Dioniso y la glorificación y exaltación de la monarquía, y desde luego, en nuestra opinión, en relación con un indudable poder económico de estas cofradias ${ }^{28}$.

Rostovtzeff, M. Historia social y economica del mundo helenistico. Espasa Calpe 1967. t. II. pág. 713 .

Preaux. Cl. Le monde hellénistique. cit. pág. 713

OGIS 311

OGIS 326

OGIS 325

Sobre los technitai en general cfr. POLAND. F technitai, RE S.v.; asimismo HANSEN, E.. The Attalids of Pergamon, págs. 409-410: también RoBERT. L., Etudes de Numismatique Grecque. Paris 1962: Idem. Documents de l'Asie Mineure Meridionale: Inscriptions, monnaies, geographie. Paris-Ginebra 1966: Idem. Monnaies grecques. París-Ginebra 1967; Idem. en Études Anato. iiéens, págs. 39-44: WelLES, Royal Correspondence, cit. núms. 53, 65 y 66. También los Lágidas. como los Atálidas, desarrollaron un "dionisismo real", y muchas asociaciones de technites de Dioniso servian también al culto de sus soberanos. bien entendida de una manera griega, e incluso los atalistas de Teos habian dedicado cerca del teatro un Attaleion o sede del culto a Ios Atálidas, cfr. WELLES, C. B. Royal Correspondence in the Hellenistic Perrod. New Haven 
Desconocemos hasta qué punto estas corporaciones llegaron a contribuir a las primeras emisiones de los cistóforos, pero su poder económico y su influencia en la política atálida es evidente por estas emisiones monetarias.

Esta dimensión económica se puede añadir al carácter religioso y social que tenian las asociaciones de comerciantes en el mundo helenístico, cuyo papel cosmopolita era evidente en el ámbito comercial ${ }^{29}$. Entre los templos y las bancas privadas y públicas en este momento parece que existió más colaboración que competencia, lo que viene a demostrar una vez más la intima conexión entre poder político, económico y religioso en el mundo antiguo, idea sobre la que ya hemos hablado más arriba y a la que volveremos a referirnos más adelante.

Un posible precedente de estas acuñaciones, influenciadas, si no dirigidas, por los Dionysiaikoi Tchnitai, se encontraría en la ciudad de Cízico. donde existía una corporación religiosa de similares características. Aquí, se emitió una moneda en la que se mostraba la unión de Core y Dioniso joven en un carro, arrastrado por centauros, en medio de una pompa báquica, precedidos por Eros. En esta misma escena, se muestran espigas y adormideras, como en la célebre escena representada en el camafeo del Cardenal Carpegna, actualmente en el Museo de Louvre (fig. 7) ${ }^{30}$.

Cuando Atalo III dejó en herencia su reino a Roma, los cistóforos se convirtieron en la moneda oficial y local de curso legal de la nueva provincia romana de Asia. Se las distingue de las anteriores emisiones a partir de aquí porque llevan los nombres y los simbolos de las ciudades que las emiten, los nombres y monogramas de los magistrados monetales y la fecha de la era en que se creó la provincia consular.

Aunque brevemente, por las características de este trabajo, no podemos dejar de aludir aqui a los tipos iconográficos que se eligieron para ser grabados en el anverso y el reverso de los cistóforos. Estos tipos tienen importancia, en nuestra opinión, ya que las monedas no eran solamente parte de una transacción comercial, sino que ponerlas bajo la advocación y la protección de un dios determinado podía significar su garantía económica por los depósitos de los diferentes templos de dichos

1934 Idem, "Hellenistic Tarsus", en Melanges de l'Université de s. Josep. Beirut 1962, págs 41-76: Idem, "The Ptolemaic Administration of Egypt", Journal of Juristic Papyrology 3, 1949. págs. $21-47$; Idem. "The role of the Egyptians under the first Ptolemies", Bulletin of the American Society of Papyrologyst 7, 1970, págs. 405-510

"SChnelder, C., Kulturgeschichte des Hellenismus. Munich 1969, t. II, págs. 108-104

Daremberg-Saglio, fig. 719, tomado de Muller y Wieseler, t. II. pl. X, núm. 115. 


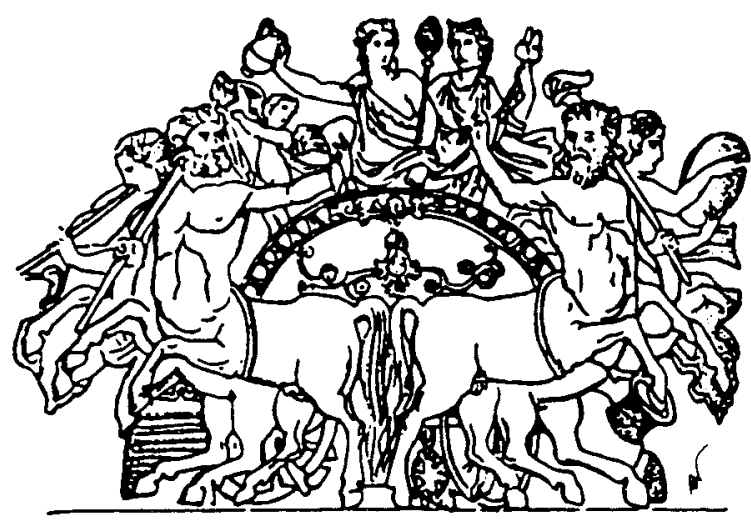

Fig. 7. Camafeo del cardenal Carpegna (Louvre). Core con espigas y capsulas de adormidera y Dioniso joven en un carro tirado por centauros

dioses a cuyo papel en la economía de la antigüedad, como veremos más abajo, se han referido numerosos autores antes que nosotros ${ }^{31}$.

Tampoco debian herirse susceptibilidades, ya que estas monedas estaban dirigidas a un amplio espectro de gentes de toda clase y condición, tanto de nivel social como espiritual. Por ello, los tipos elegidos para unas monedas a las que se quería dar una máxima difusión y credibilidad debian tener una significación universal, «internacional». Y aunque los nombres y las imágenes de las diferentes divinidades elegidas como tipos no fuesen iguales en los diferentes paises, sus figuras o sus simbolos debian corresponder a la misma divinidad. Así, se eligieron como tipos divinidades muy conocidas en todo el área del Egeo y el Próximo Oriente, a las que no dudamos en calificar de «internacionales".

Entre estas divinidades o símbolos, cuyo culto estaba ampliamente extendido por el mundo egeo oriental destacan Artemis, Heracles, Deméter y Core y sobre todo la hoja de vid, simbolo para Grecia y Roma, de Dioniso.

Como veremos más abajo, estas divinidades, tan dispares entre sí, están unidas por un tema común: la serpiente que a veces las acompaña

Bogaert. R. Les origines antiques de la banque de depôt. Une mise au point d'une esquisse des operations de banque en Mesopotamie. Leiden. A. W. Sithotf. 1966 págs. 43-63. 


\section{b) La serpiente en otras monedas griegas}

La serpiente aparece a menudo como tipo en diferentes monedas griegas, tanto en anversos como en reversos, desde época temprana hasta bien avanzada la época imperial romana ${ }^{32}$ acompañando a diferentes divinidades como abajo veremos, tales como Esculapio e Higia, Apolo o Zeus $^{33}$, ninfa o ménade ${ }^{34}$, Atenea ${ }^{35}$, Hermes-Mercurio ${ }^{36}$, Heracles, Po-

PLANT, R. Greek coin types and their identification. London 1979, s.v. Snake.

PIANT: op cit I. TRIO MEDICO: APOLO-HIGIA-ASCLEPIO. Diferentes monedas: 1. La ciudad de Caria, Halicarnaso, en alianza con Cos, 198-212 d.C., presenta a Apolo con la lira y a la derecha Asclepio con su vara. alrededor de la cual se enrolla una serpiente. En el anverso el busto de Caracalla a la izquierda y el de Geta a la derecha. PLANT, op. cit., núm: 7 . AE 34 2. Caria. Attuda, epoca imperial. Reverso, Higia y Asclepio a su izquierda mirando hacia la derecha: anverso, busto del Senado, Plant, op. cit., núm. 20; 3. En Capadocia, Tiana emite en 198-217 d.C. una moneda, con Higia a la izquierda y Esculapio a la derecha. En el anverso la cabeza de Caracalla. Plant. op. cit., núm. 30, AE 28; 4. Misia, Pérgamo, 133-67 a.C., Asclepio con serpiente en anverso y busto de Atenea en el reverso, PLANT, OP. cit., núm. 340, AE 25; 5. Rodas, 43 a.C.-96 d.C., Esculapio en anverso y cabeza de Helios en reverso, PLANT, op. cit., num. 341. AE 18:6. Frigia. Acmoneia. siglo Ia.C.. Esculapio en anverso y cabeza de Zeus en reverso, PLANT, Op. cit, num. 342, AE 16-18; 7 . Lidia, Hipaepa, época imperial romana. Esculapio-cabeza de Hercules. PLANT, op. cit. núm. 343, AE 18; 8. Lidia, Magnesia del Sipilo, época imperial romana. Esculapio-cabeza barbada del monte Sipilo. PLANT, op. cit., núm. 344, AE 20. Aeolis, Elea, epoca imperial romana. Esculapio-cabeza del Senado, Plant, op. cit., núm. 345. AE 20; 10. Frigia, Docimeio, época imperial romana, Esculapio Joven-cabeza de Docimos, fundador legendario, PLANT, op cit, núm. 346, AE 19;11. Provincia de Tesalia, 31 a.C.-14 d.C., reverso, Esculapio; anverso, cabeza de Augusto. Plant, op. cit., núm. 347, AE 19; 12 . En Frigia, Aezanis, $117-137$ d.C.. Esculapio-Busto de Sabina, PLANT, op. cit., num. 348, AE 19; 13. Frigia. Acmoneia, 161-180 d.C., Esculapio-Cabeza de Marco Aurelio. PLANT, op. cit., num. 349. AE 18. 19: 14. Misia, Hadrianotera, 193-211 d.C. Esculapio-Busto de Septimio Severo. PLANT. Op. cit.. num. 350, AE 19; 15. Islas cercanas a Lesbos, Pordosilene, 193-211 a.C., Esculapio-Busto de Septimio Severo, PLANT, núm. 351. AE 16; 16. Lidia. Acraso, 193-211 d.C., Esculapio-Busto de Septimio Severo, PLANT, núm. 352. AE 17-19: 17. Tracia, Topiro, 198-217 d.C., Esculapio-Busto de Caracalla, Plant, núm. 353, AE 18; 18. Cilicia, Eleusa-Sebasté, 222-235 d.C.. Telestoro a la derecha de Esculapio-Busto de Alejandro Severo, PLANT, núm. 354, AE 34; 19. Argólida. Epidauro, 138-162 d.C., reverso Asclepio con serpiente-Busto de Antonino Pio, AE 25, 20. Macedonia, Dium, 235-238 d.C., Esculapio-Busto de Maximo César, Plant, núm. 355. AE 25; 21. Tracia, Deultum, 244-249 d.C. Esculapio-Filipo Il el Arabe, PLANT, núm. 356. AE 19. Higia con patera y serpiente en la mano derecha es otra de las divinidades que aparece en las monedas griegas. Personificación de la salud, esta divinidad es considerada como hija de Asclepio. No posee ningún mito particular y sólo figura en el cortejo de este dios. La vemos en las monedas siguientes: 22. Isla de Caria, Cos. época imperial romana. Higia-Cabeza del médico Jenofonte. PLANT, núm. 357, AE 18:23. Cilicia, Irenepolis, 81-96 d.C. Higia con una rama, una patera y serpiente-Cabeza de Domiciano, PLANT, núm. 358, AE 22; 24. Bitinia. Tium, 138-161 d.C.. Higia. Busto de Antonino Pio, PLANt, núm. 359. AE 20, 25. Tracia, Trajanopolis, 193-211 d C., HigiaCabeza de Septimio Severo, Plant, núm. 360. AE 29: 26. Frigia, Bruzus, 193-211 d.C. HigiaBusto de Septimio Severo. Plant, núm. 361. AE 26: 27. Laconia, Las, 209-212 d.C. Higia-Busto de Geta, Plant. num. 362. AE 26: 28. Mesia inferior, Marcianopolis, 218-222 d C. Higia Busto de Heliogábalo, P Ant, num. 363, AE 25; 29. Misia, Pérgamo. 253-268 d.C. Higia-Busto de SaIonina. Plant, num. 364. AE 28; 30. Tesalia, Tricca, 400-344 a.C. Asclepio con cetro, pajaro y serpiente-cabeza de la ninfa Trica hija del dios-río Peneo, en Tesalia y esposa del rey Ipseo. PLANT, núm. 697, AE 25: 31. Argólida, Epidauro. 350-323 a.C., estatua de Asclepio, hecha por 


\author{
seidón, Deméter ${ }^{37}$, etc., algunos de los cuales examinaremos, como he- \\ mos dicho, más abajo.
}

Trasimedes de Paros. Lleva un cetro en su mano izquierda y extiende su mano derecha hacia la cabeza de una serpiente. Junto al trono del dios hay un perro-Cabeza de Apolo. Dracma, $67 \mathrm{~g}$, Plant, núm. 698; 32. Argólida, Epidauro, 138-161 d.C., Asclepio-Busto de Antonino Pio; 33. Con la imagen de Zeus Laodiceo y Esculapio vemos otras monedas: PLANT, núm. 29, emitida en Laodicea, en Frigia, en alianza con Pérgamo, 198-217 d.C. En el reverso figura el tipo de Zeus Laodiceo con un cetro y un águila, a la izquierda y a la derecha Esculapio. En la otra cara un busto de Caracalla, $A E 28 ; 34$. En Creta, Gortina emite una moneda con Atenea en reverso con serpiente en la mano. En el anverso la cabeza de Zeus, PLANT, op. cit., núm. 133. AE 21; 35. Mesia inferior. Dionisopolis, dos bustos enfrentados-Higia, PLANT, núm. 736: 36. Brutio, Regio, Cabeza de Jano en anverso-Esculapio sentado con serpiente, PLANT, OP. cit., núm. 742. A veces aparece también en las monedas el motivo del carro tirado por serpientes

34 En Pisidia, Etenna, en el siglo 1 a.C., en el reverso, una figura femenina (¿Ménade?) con una serpiente, PLANT, op. cit., num. 42. AE 13

35 Atenas en época imperial romana, emite una moneda que lleva en el reverso la figura de Atenea con la serpiente a su derecha. En el anverso la cabeza de Atenea. PLANT, núm. 118 , AE 22

35: Hermes aparece en la forma clásica. con caduceo con dos serpientes enroscadas, el petasos en la cabeza y las sandalias aladas. Asi, en Regio. Brutio, en una emisión de 283-89 a.C. vemos a Hermes con caduceo y a los Dióscuros en el anverso con estrellas sobre la cabeza. PLANT, op. cit. núm. 322, AE 16. En Frigia, Temenotira Flaviopolis, en época imperial romana, emite moneda en la que vemos en el reverso Hermes con el caduceo, petasos y bolsa en la mano derecha. mirando a la izquierda y en el anverso el busto de la diosa de la ciudad. PLANT, op. cit, núm. 323, AE 23. En Cilia, Corico emite moneda en cuyo reverso vemos a Hermes con pátera y caduceo. En el reverso la cabeza de la divinización femenina de la ciudad Plant, op. cit., num. 324, AE 21-22. En Frigia, Dionisopolis, en época imperial romana emite monedas cuyos tipos son cabeza de Serapis en anverso y en el reverso Hermes-Mercurio con el caduceo y bolsa en la mano derecha. PLANT. Op. cit., núm. 325, AE 20. En Tracia, Aenos, en el siglo $\|-1$ a.C. . emite moneda con Hermes en el reverso ante un altar y en el anverso la cabeza de Poseidón, Plant, op. cit., núm. 326. AE 24. En Lidia, Blaundus, en el siglo 1.t a.C., emite monedas con Hermes-Mercurio con el caduceo. En el anverso la cabeza de Zeus. PLANT, OP. cit. num. 326. AE 24. En Cilicia. Adana, desde el 164 a.C. a época imperial, emite monedas cuyos tipos son en reverso Hermes con el caduceo y en anverso la cabeza de ZeUS. PLANT, op. cit. núm. 328, AE 19. En Creta. Lato, emite de 200 a 67 a C., monedas con Hermes con el caduceo y pequeña aritorcha y cabeza de Artemis. PLANT, op. cit., núm. 329, AE 14. En Tracia. Sestos, emite hacia el 300 a.C.. moneda con Hermes con el caduceo y ánfora y cabeza de Demeter. Plant. op. cit. núm. 330. AE 16-17. En Arcadia, Feneo de 326 a 300 a.C. emite moneda con Hermes frente al joven Arcas-Cabeza de Demeter. de $185 \mathrm{~g}$, estátero, PLANT, op. cit. núm. 331, AE 24. En Sicilia, Corico, en época imperial, emite monedas con Hermes-Mercurio con caduceo y bolsa y cabeza femenina, tal vez de Afrodita. PLANT. op. cit. núm. 332, AE 28. En Bitinia, Nicomedia, emite del 138 al $168 \mathrm{~d}$.C. con los tipos de Hermes y busto de Antonino Pio. Plant, op. cit. núm. 333, AE 17. En Frigia, Acmonela del 238 al $244 \mathrm{~d}$ C. emite moneda con Hermes y el carnero y busto de Gordiano III, PLANT op. cit., núm. 334. AE 26. En Panfilia. Megido, de 244 a 249 d.C.. emite con el tipo de Hermes con el carnero y el busto de Filipo el Arabe. Plant, op. cit., núm. 335. AE 24. En Caria. Afrodisias, desde el 253 al 268 d.C., emite monedas con Hermes con carnero y busto de Salonina sobre creciente lunar. PLANT, OP. Cit. núm. 336. AE 22-23. En Arcadia, Feno. de 362 a 300 a.C., emite moneda con el tipo de Hermes en cuyo caduceo vemos las serpientes. sentado sobre una roca (monte Cileno) y en el anverso la cabeza de Deméter de $86 \mathrm{~g}$. dracma. PLANT. Op cit. núm. 703. AR 19. Y finalmente, en mo nedas de Tracia. Anquialo. del 238 al 244 d.C. vemos en el anverso un busto de Gordiano III y a su izquierda Tranquilina. En el reverso Hermes sentado con bolsa y caduceo. PLANT, OP. cit.. núm. 735. AE 26. 


\section{c) La serpiente en la numismática ibérica}

En la Península Ibérica se encuentra también el tipo de la serpiente en algunas monedas. Así, en Cartago Nova (Cartagena, Murcia), donde se conocen las acuñadas por los partidarios de Pompeyo, durante las guerras contra César y luego por los duunviros quinquenales, que recogen varias veces el tipo de la serpiente como característico y peculiar. Y una alusión, la clara abreviatura de SALVS, que no es difícil que fuese la divinidad principal, teniendo como agregado y secundario a Esculapio hasta que su difusión por el Imperio hizo que éste tomase mayor impor-

Entre otros tipos, ademas de los arriba citados vemos la emisión de Creta donde en Prianso del 430 al 300 a.C. emite una moneda en cuyo reverso se ve una diosa acariciando una serpiente. Tras ella una palmera. mientras que en el reverso aparece Poseidón con delfin y tridente. Pesa $169 \mathrm{~g}$ y es un estátero. PLANT, op. cit. núm. 700. AR 24. En Atenas. en época imperial romana, se emite una moneda en cuyo reverso figura Deméter con antorchas y trigo en un carro conducido por serpientes. En el anverso figura una cabeza de Atenea. PLANT. op. cit., núm. 882. AE 20-22. En Galatia. Pessino, de 198 a 217 d.C., emite moneda con el tipo de Deméter en el carro y busto de Caracalla. PLANT, op. cit., núm. 884. AE 29. En Alejandria se emite también, del 98 al 117 d.C. moneda con el tipo del modius conteniendo grano en un carro conducido por dos serpientes ondulantes. Ilevando cada una una corona egipcia en el reverso. mientras que en el anverso figura el busto de Trajano. PLANT, núm. 885. AE 33 y con Triptolemo en un carro conducido por dos serpientes ondulantes, PLANT, Op. cit., núm. 886 , entre los años 161-169 d.C. En Misia. Pérgamo, en 133 a.C. emite tetradracmas con la cista mistica con serpiente rodeada de una corona de hiedra en el anverso y en el reverso un arco en su funda con serpientes entrelazadas a su alrededor, de $165-195 \mathrm{~g}$ de peso. PLANT, Op. cit, núm. 2084, AR 25-28. Este tipo de tetradracma cistóforo fue emitido por otro gran número de ciudades: Efeso y Esmirna en Jonia. Tiatira. Sardes y Tralles, en Lidia, Apamea y Laodicea en Frigia y Nisa en Caria. En época romana, los cistóforos se mantuvieron durante algunos años. Asi, en Jonia. Magnesia emite de 198 a 217 d.C., con el tipo de cista mistica y serpiente y en el reverso el busto de Caracalla. PLANT. op. cit., núm. 2086, AE 22. Fenicia. Sidón. del 64 al 63 a.C. al 116-117 d.C. emite moneda con la cista mistica rodeada de hiedra. En Eubea. Calcis emite moneda con proa en el anverso y en el reverso águila y serpiente. También recoge este autor serpientes con la vara de Esculapio, los núms. 114. de Pérgamo. en Misia de los anos 200-133 a C.; el núm. 115. de Dirracacio, en lliria. del 229-100 a.C., el núm. 116 de Laodicea. en Frigia, del 31-14 a.C.: el núm. 117, de Cos, en la isla de Caria que emite del 98 al 117 d.C. En otras monedas figura el tripode de Delfos y a su alrededor una serpiente. asi en la emitida por Lilibeo, en Sicilia, del 241 a.C. PLANT. op. cit., núm 2422; la emitida por Pérgamo. en Misia, del 193 al 217 d.C. Sobre las monedas helenísticas cfr. BOEmRinger. C. Zur chronologie mittel hellenistischer münzserien 220-160 v. Chr. Berlin 1972. Sobre los lágidas. MiLNE. J. G.. "The currency reform of Ptolomy Il". Ancient Egypt 1928, págs. 37 y Ss.: PrEAux. Cl. L'économie royale des Lagides. Bruselas 1939; REINACH. T., "Du raport de valeur des mètaux monetaires aux temps des Ptolomées». Revue d'Études Grecques 41, 1928. pág. 121. Sobre la economia capadocia Morkolm. O., "Some Cappadocian Dielinks", Num. Chron. VII, 4, 1964. págs. 21 y sS.: SimONetTA. B., "Notes on the coinage of the Cappadocian Kings". Num. Chron. VII. I. 1961. págs 9 y SS.: LEWIS. D. M., "The Chronology of the Athenian new style coinage". Num. Chron. VII, 2, 1961. págs. 107 y ss. Sobre los Atalidas cfr. HANSEN. E. V.. The Attalids of Pergamon. Ithaca-Londres 1971, sobre los cistóforos cfr. págs. 116 y 475. VAzQUEz HoYs. A. M." El mundo griego. cit en nota 10 supra. 
tancia. También existen monedas unciales con el tipo de la serpiente en la Península Ibérica, como los semises de Cartago Nova, donde en época republicana romana se acuñó un as en cuyo anverso vemos una cabeza de Jano con las dos caras laureadas separadas por un ara, alrededor de la cual se enrolla una serpiente. Encima MAGN, debajo PIVS IMP. F. En el reverso, una proa de nave a la derecha. Encima EPPIVS y debajo LEG.

Esta moneda pertenede a M. Eppio, uno de los principales jefes pompeyanos en España que luchó como lugarteniente de Sexto Pompeyo, cerca de Cartagena, contra los generales de César, Carrinas y Asinius Polio. Según Daremberg-Saglio, esta moneda conmemora la dedicación del templo de Esculapio en Roma, en la isla tiberina.

También en la moneda que lleva en el anverso una cartela de L. FABRIC, atravesada por otra perpendicularmente, de formas diversas y $\sin$ rótulo, en el reverso, figura una serpiente, debajo P. ATELLIV. Se trata de un ejemplar acuñado sobre un as de Belikion, de la colección Criado, de Madrid, que se puso en relación con Cirene porque alli había un famoso templo de Esculapio y una escuela de medicina ${ }^{38}$. Se conoce además el cuadrante acuñado por los duunviros quinquenales Helvio Pollio y Postumio Albino, que lleva en el anverso, en círculo, la leyenda ALBINVS/ IIQVI. En el reverso figura en circulo la serpiente enroscada y debajo en dos líneas, HEL.POLL y $\|\left. Q V\right|^{39}$.

En los ases de Carbula ${ }^{40}$ se ofrecen dos modalidades. Una la que repite la cabeza femenil de Obulco pero con sierpe delante y aspa detrás, que lleva en el reverso una lira con nombre tópico en derredor ${ }^{41}$ y otra el as ${ }^{42}$, en el que vemos una cabeza imberbe de Hércules y un caduceo,

TACITO. AnN XIV: HEROD. III. 131.

39 BeltaAn, A , «El ara romana del Museo de Barcelona y su relación con el culto de la Salud y Esculapio en Carthago Novan, en Ampurias IX-X, págs. 213-221, láms. I-II, figs. 1 a y b; Idem, "Las monedas romanas de Cartagena según sus series de monedas y lápidas latinas". Actas y Crónica del Congreso de Albacete 1947, págs. 306-325; Idem, "Las acunaciones pompeyanas de Cartagena", Anuario de Numismática. En Cartago, la serpierite aparece también como genio tutelar de Augusto y Livia, sg. Strong, Roma Antica. Bergamo 1929, pág. 149; Poinssot, L'autel de la Gens Augusta à Carthage. Túnez 1929, láms. I y XI, pero en Cartagena es muy anterior, posiblemente en relación con el dios púnico Shmoun o la Atenea Nike-Anat de Tiro, Cfr. nota 69 infra

"Wives Escudero. A.. "La moneda hispanica en la Edad Antigua". Monedas unciales de la Hispania Citerior. pág. 138.

VIVES, op. cit., pág. 141, fig. 376 y cuadro pág. 154

VIVEs op cit. núm. 652. pag. 212 
un aro y una sierpe, mientras que en el anverso figura un jinete con palma y en el exergo lauro ${ }^{43}$.

Ebussus, en el siglo ॥I a.C. emite también una moneda en la que vemos una serpiente. Se trata del tipo que lleva en el anverso el cabiro con serpiente y caduceo y una leyenda neopúnica ${ }^{44}$. $Y$ el óbolo y el medio óbolo del 238-206 a.C., en cuyo reverso vemos a Bes de frente, con las manos en el vientre sosteniendo martillo y sierpe. En el anverso, el tipo es un toro parado con cabeza de frente ${ }^{45}$. El mismo tipo de reverso se aprecia en las monedas de $1 / 2$ calco que tienen en el anverso la cabeza de Astarte hacia la izquierda ${ }^{46}$.

Todas esta monedas repiten de una u otra forma el tipo de la serpiente como una constante, como una divinidad, genio o fuerza benéfica, de la que a menudo desconocemos su significación, aunque no podemos dudar de su carácter, digamos, "positivo" que en otras ocasiones hemos resaltado ${ }^{47}$.

4., Vives, págs. 246 y 249. Emisiones locales de la Hispania Citerior IV. Cargago Nova, num. 1042, semis tipo L. ABRIC./P: ATELIV. con sierpe enroscada, ya que carece de quinquennales, pero su fecha es incierta y su atribución a esta ceca es totalmente dudosa. Idem, pág. 248 . también de Cartago Nova, dentro de la dominacion cesariana, vemos diferentes tipos: Sierpe (num. 1042), pág. 274; Usecerte (Osicerda. Conv. Caesaraugustanus), núm. 1135. As, 45 a.C.? Tipos: Anverso: Victoria avanzando con laurea en diestra, delante OS/Reverso: Elefante pisando sierpe. Abajo USECERTE (ibérico). Ref. v-72:2. También en Carbula (Almodóvar del Río, Córdoba) se acuña un as con cabeza de Febo y sierpe delante/Lira con tópico latino alrededor. De situación incierta es la ceca que acuña hacia $47-44$ a C. una moneda que lleva por tipo a Hércules nacia la izquierda con piel de león y maza delante, Vives, núm. 1367, pág. 309 delante $P$ TERENT BODO/Jabali con sierpe enroscada, arriba epigrafe libiofénice, abajo L. NUMIT. BODO, laurea alrededor. También el as de Carbula, VIVEs, núm. 1185, pág. 343, del 67 a.C., con cabeza laureada de Febo y delante sierpe y lira

A PLANT, op. cit., núm. 339. AE 21

4: VIVES, op cit, ref V-11:1, pág. 69

HIVES, op cit, pág. 70, ref. V-11:18

$\because$ Vazouez Hors. A. M.". "La serpiente en el mundo antiguo I. La serpiente en las religiones mediterráneas". Boletin de la Asociación de Amigos de la Arqueologia 14. diciembre de 1981. págs. 33-39: BRU ROMO, M y VAzOUEz HOYS, A. M.". "The representation of serpent in Ancient Iberia". International Conference on Archaeology and Fertility Cult in Ancient Mediterranean. Mal. ta 2-5 de septiembre de 1985, ed. Malta, 1986, págs. 305-314: Idem. "From earth to heaven: The snake and the indoeuropean religious change". The Transformation of European and Anatolian culture 4.500-2.500 B.C. Dublin, organized by the Indo-European Studies Program, Uni versity of California, Los Angeles, in conjuction with University College, 15-21 de septiembre de 1989. en prensa: Idem, Munoz Garcia-Vaso. J., "Representaciones de serpientes en el culto mitraico". Espacio, Tiempo y Forma. Madrid Revista de la Facultad de Geografia e Historia. UNED. serie II. Historia Antigua, 1990. t. III, págs. 85-116; Idem,-- DEL Horo CaLlEJA, J.. "La Gorgona y su triple poder mágico (Aproximacion a la magia, la brujeria y la superstición. II)". Espacio, Tiempo y Forma. Madrid 1990, 1. Ill. pags. 118-182; Idem.--.- Fennandez UhiEl, P. "Los cistóforos y su significado". Boletin de la Asociación de Amigos de la Arqueologia, jullo-diciem. bre de 1990. num. 29, pags 48-61 


\section{LA SERPIENTE Y LOS DIOSES PAGANOS EN LAS MONEDAS}

\section{a) Asclepio e Higia}

Recuerda C. Meslin al referirse a la simbologia religiosa, que el significado de la serpiente es uno de los más importantes de la historia de la humanidad y refiere cómo a un simbolismo fundado en los caracteres de un animal se une un cierto número de valores religiosos opuestos ${ }^{4 k}$.

A menudo, la serpiente aparece ligada al mundo de ultratumba, como símbolo de la muerte y del mal. Su aspecto es repulsivo y se la asocia, generalmente, con la idea de un genio del mal, de las tinieblas, de un ser que proviene de la tierra.

Representa a veces el poder del rey, como en Egipto, y es objeto de culto en numerosos santuarios de Grecia. Guarda las tumbas y se la asocia también con el espíritu de los muertos. Representa la fuerza fecundante de la tierra cuando es un animal fálico, extraña paradoja que la hace andrógina. $Y$, digamos, cerrando ya el círculo de sus múltiples significados (que no hemos agotado ni mucho menos), que también representa al sol, siendo el simbolo solar. Y la serpiente que se muerde la cola es el reflejo de la eternidad. Conocemos asimismo, por algunos textos clásicos, su conexión con elementos relacionados con la muerte, como ya dijimos, el sueño eterno y las creencias en la resurrección, es profética y está también relacionada con la fecundidad y la magia ${ }^{49}$.

Otras veces, la serpiente es el animal que representa los poderes demoníacos, negativos, al mismo demonio que se opone a la divinidad principal de un panteón. También está ligada al mundo funerario, a la tierra y a la muerte, pero también a la vida eterna ${ }^{50}$. Un análisis exhaustivo de su significación excedería los límites de este trabajo, además de nuestras

44 Meslin, C. "Hermeneutica des symboles religieux", en MENARD. J. E. (ed.). Le symbole. Estrasburgo, Faculté de Théologie Catholique, 1975. págs. 24-32, pág. 26

"VAzOUEZ Hors, A. M.", "La serpiente en el mundo antiguo. I. La serpiente en las religiones mediterráneas". Boletin de la Asociacion de Amigos de la Arqueologia, diciembre de 1981, núm. 14. págs. 33-39.

Burton Rusell. J., The Devil's Perceptions of Evil from Antiquity to Primitive Christianity. Londres 1987; Gedion. S., El presente eterno. Los comienzos del arte. Madrid, Ed. Alianza, 1981. pág. 118; ELIADE, M. Historia de las creencias y de las ideas religiosas I. Madrid 1978, pág. 471; Tovar. A., Vida de Socrates. Madrid, Alianza Universidad, 1984, pags. 259-275; vid. tambien, entre otros DumezIL, G. La religion romaine archaíque. Paris, Payot, 1987, 2. "ed., págs. $55,56,60,61,119,300-301,362-369,505-507,600-601$ : GRIMAL, P. Diccionario de la Mitologia griega y romana. Barcelona. Ed. Paidós, 1982, pág. 213: Gundel. H G. Weltbild und Astrologie un den griechischen Zauberopapyri. Munich 1968, pag. 78, cit por FEhNande i MarCOS, N., "Mo- 
posibilidades en este momento, ya que su carácter varia en las diferentes culturas, lo que dificulta enormemente la comprensión de su significado, al que nos hemos acercado en numerosas ocasiones ${ }^{51}$.

También la serpiente, animal de significado polivalente, está unida a los cultos de las divinidades ctónicas y de la fecundidad, de la salud, como Asclepio e Higia y a gran cantidad de héroes y semidioses, siempre como un animal benéfico, como una expresión de la divinidad, dispensadora de bienes, salud y profecias, considerada como inmortal porque renueva su piel en primavera y renace cada año, como la vegetación. La serpiente era, en Grecia y Roma, el animal simbólico del dios de la medicina, Asclepio-Esculapio, y también en el Próximo Oriente. En Hatra, este dios era Ba'al Shamin, que tiene también como animal acompañante una serpiente ${ }^{52}$.

Y también acompaña la serpiente al Esculapio sumerio, Ningizzida, dios ctónico e infernal, adorado sobre todo por Gudea de Lagash. Este dios secundario cayó en el olvido después de la época neosumeria, pero no la serpiente, que pasó al repertorio iconográfico de Oriente, donde ya era conocida desde mucho antes, posiblemente por influencia elamita ${ }^{53}$, donde desde época muy antigua, tal vez desde el Neolítico, la serpiente está asociada con la mujer, la fertilidad y la abundancia.

Ambos dioses de la medicina citados, parecen ser los precedentes del dios de la ciudad siria de Palmira, Shadrafa, dios de la salud, al que se

tivos judios en los papiros mágicos griegos". en Religión, superstición y magia en el mundo romano. Cádiz. Departamento de Historia Antigua, Servicio de publicaciones, Universidad de Cádiz, 1985, núm. 69, págs. 101-127, 115.

Además de los trabajos citados en anteriores notas hemos dedicado a la serpiente otros numerosos trabajos, VAzQuez HoYs, A. M. "VAzQUEZ Hoys, A. M." "La serpiente en las religiones antiguas, ¿genio o demonio?", Actas del I Congreso de Arys, Heroes y semidioses y daimones. Jarandilla de la Vera, Cáceres, diciembre 1989, ed. Madrid 1992, págs, 81-134; ldem, "La miel, alimento de eternidad". Homenaje a M. Posich. Universidad Complutense, Madrid. Anejos de Gerion 1992, págs. 31-47; Idem, "Aquella que ama el silencio: La serpiente en el Antiguo Egipto", Espacio. Tiempo y Forma. Madrid, UNED, serie II, Historia Antigua, 1991, núm. 4, págs. 37-72; Idem, "Dioses y diosas del Próximo Oriente y las serpientes", 3è Congrès International d'Etudes Pheniciennes. Túnez noviembre de 1992, en prensa. Idem: “Dioses y diosas en forma de serpiente y su culto en Egipto: Isis-Thermouthis, Serapis-Agathodaimon" Homenaje a F. Pre sedo, Sevilla 1993, págs 99-119; idem; "La serpiente en la epigrafia hispana", Homenaje a $M$. Le Glay, en prensa.

DU MESNil du Buisson, C., "De Shadrapha, dieu de Palmyre à Ba 'al Shamin, dieu de Hatra, aux llè et lllè. siècles aprés J. C.", en Mélanges de l'Université Saint Joseph 38, Beirut 1962, pags. 143-160. Sobre la serpiente de bronce cfr. KaUfManN, Y., The Religion of Israel, págs. 83, 137, 147-148, 237, 286. Sobre los beneficios del veneno de las serpientes cfr. FoLCH ANOREU. R., "Las serpientes y sus venenos. Medicamentos que con ellos se han preparado" Farmacia Nueva. Madrid 1959, núms. 273, 274, 275.

$\therefore$ VAzQuez HoYs. op. cit, en 3è. Congrès d'Études Pheniciennes, en prensa. 
representa a menudo con una larga lanza, alrededor de la cual se enrolla una serpiente ${ }^{54}$

Para Fevrier ${ }^{\text {sh }}$, este dios puede relacionarse con Ningizzida, Reshef y Heracles, por sus atributos; el león, y también la serpiente, que a veces acompaña a estos dioses.

También Apolo Hierapolitano, como refiere Macrobio, en el siglo v d.C. ${ }^{36}$ tiene relación con las serpientes, describiendo una imagen que se veneraba en el gran templo de Hierapolis, en Siria. Se representaba al dios con barba, y detrás de él águilas a punto de levantar el vuelo. Ante sus pies, una imagne femenina a derecha y a izquierda de la cual se ven estatuas femeninas rodeadas por una serpiente.

En la espalda lleva un manto que Macrobio describía como velamentum gorgoneum, en cuyo centro se aprecia una cabeza de Gorgona, con el cabello anudado bajo el mentón y dos pequeñas alas en lo alto, con toda la superficie del manto cubierta de escamas, "de piel de serpiente" (escamoso), lo que significaba para Du Mesnil du Buisson detentar la inmortalidad divina, pues se creía que la serpiente era un animal inmortal, ya que mudaba su piel todos los años y renacía, siempre joven, episodio que vemos en el Poema de Gilgamesh, en el que, cuando la serpiente se apodera de la planta de la vida, muda sus escamas y renace ${ }^{57}$

\section{b) El Agathós Daímon}

Pero también, en general, casi todos los autores están de acuerdo al afirmar el carácter funerario de la serpiente y a menudo la vemos representada en el mundo romano en estelas y aras funerarias representado los Manes y el alma del difunto. Aunque también es en el mundo griego la imagen benefactora del Buen Espíritu (Agatodaimon) y su presencia

-Starcky, J., “Autour d'une dédicace palmyrénienne a Shadrafa et à du Anat", Syria 26 1949, págs. 43-85, 73. Sobre Ningizzida, dios sumerio de la fertilidad ctr. la monografía de VAN BuAEN en Iraq I, 1934, págs. 60-89. También en la misma revista FRankfort, H., págs. 8-17 y COPPENS, J., "La connaisance du bien et du mal et le péché du Paradis", Idem pág. 91. También VAN BuREN, E. D., "Entwined serpents". Archiv. für Orientforsch. X, 1935-1936, págs. 54 y ss

Fevrier, J. G. Religion des Palmyréniens, cit por StaRCky, op. cit., pág. 68

st Saturnalia I, 17,67.

57 Serrig en Syria, 1949, págs 17-28. Las águilas figuran también a veces a los lados del omphalos de Delfos, sg. Seyaig, op. cit., fig. 3, pág. 29. En el reverso de la medalla, un águila tiende a la divinidad, según DU MESNIL DU BUISSON, un símbolo de inmortalidad, en algunos casos, una serpiente, cfr. DU MESNIL DU BUISSON, C., "De Shadrafa, dieu de Palmyre à Ba'al Shamim, dieu de Hatra..", cit., pág. 146. Sobre Gorgona Cfr. nuestro trabajo en el tomo 5 de esta revista. 
significa la riqueza y la prosperidad de las casas, de los hombres que las habitan $y$ de los pueblos y naciones que las adoran ${ }^{58}$.

Es el buen genio dispensador de bienes y dador de riquezas, tan popular en Oriente durante la época helenística como en Roma (Bonus Eventus ${ }^{59}$ ), al que vemos frecuentemente representado en los lararios de Pompeya $^{60}$. Agatodaímon era originariamente el antepasado masculino, Ilamado asi de una forma eutemistica. Era dispensador de fertilidad y riqueza, una suerte de Zeus Ctonio o Plutón, al que se representaba con una cornucopia ${ }^{61}$.

Tenía como simbolo la serpiente o el falo, como los Genii locorum, emblemas ordinarios de fecundidad según $E$. Saglio. Según la Suda, Hesiquio ${ }^{62}$, Diodoro y otros autores ${ }^{63}$, los antiguos tenian la costumbre de hacer una libación al Buen Espíritu después de comer. Le estaba dedicado el segundo día del mes y en Atenas sobre todo, el día en que se gustaba por primera vez el vino de la nueva cosecha ${ }^{64}$. Este Buen Espíritu puede aparecer también en plural y según los datos arqueológicos fue adorado en Atenas, Tespias, Tebas, Orcomeno, Levadeia, Tegea, Epidauro, Delos, Tera, Rodas, donde existía una asociación religiosa llamada Agatodaimonistai ${ }^{65}$ bajo su advocación, cuya organización era la de los thiasos, en Sicilia (Siracusa y Palermo), en Alejandria ${ }^{66}$, en Milasa ${ }^{67}$ y en Caria ${ }^{68}$.

Frazer, J. G. El folklore en el Antiguo Testamento. México. Fondo de Cultura Económica. 1981. "La caida", págs. 26-49; caida del hombre. págs. 26-27, 29, 30-31, 540-541; la serpiente que muda la piel, págs. 30, 44-47; inmortal, págs. 30,40-42, 46, 48; en el arca de Deucalión. pág. 93; espiritus del agua que adoptan su forma, pág. 341.

Cook, A. B. Zeus II, I, pág. 1127, donde se refiera también a la serpiente en Alejandría y su relación con Alejandro Magno /ul. Valer 1, 28; PSEUDOCAL 1, 32.

(1) Cook, A. B., Zeus 1I, I. Nueva York 1965. págs. 1112, 1125. Sobre los lararios de Pompeya cfr. ORR, D. G. EN ANRW II, 16, 2, 1557-91. Sobre Bonus Even tum en Hispania, cfr., VAZQUEZ Hoys, A. M." en Dianium V. 1990. págs. 143-166, pág. 145 y mapa de las Abstracciones divi. nizadas.

6. Plut, Timol. 47, Cornut 27; Ael, Anim. Hist. IX, 39; Paus. IX, 39, 4

HEsIO., S.V. Agathou Daimonos

Diodoro, IV, 3; Athen 1I, 7, 384: XV, 692f, 693e: Afistoph, Equ. 85.

thi Plut, Symp. qu. VIII, 10, 3

Ross, Insc. Graec. Ined. III, num. 282

4.. Según el Pseudocalistenes I, 32 (Cod. A).

ri Conocida por una inscripcion. CIG 2700b c

Tambien por una inscripción. cfr. Mirrofoulou. E. Deities and heroes in the form of sna kes. Atenas 1977. pág. 168. Existia posiblemente una relación entre el culto de Alejandro Mag no. héroe fundador de la ciudad de Alejandria y el del genius loci, el Agatodaimon de Alejandria representado en forma de serpiente, DUNAND, F. "Les répresentations de l'Agatodaimon". BI FAO 67, 1969. págs. 9-48, también TAYLOR, L. R., "The Cult of Alexander at Alexandria". Class Phil. 2. 1927. págs. 162-169: KAERST, J., "Die Begründung des Alexander und Ptolemaeerkultes in Aegypten". Rhein. Mus 52, 1897. págs. 51-58; WILCKEN. U. "Die Entstehung des hellenistis 
Se relaciona también la serpiente con otras divinidades, aquellas que representan las fuerzas de la naturaleza, la fecundidad, la vida y la muerte, como Anat, Asthart, Artemis, Hécate, etc., y el manto que recubre a Apolo Hierapolitano recuerda a la égida de los griegos, asimismo recubierta de escamas, que es un atributo de Zeus y de su hija Atenea-Minerva.

También desde época arcaica, la serpiente fue uno de los atributos de esta diosa. Su égida estaba recubierta de piel de serpiente y estaba rodeada de serpientes vivas que se arrojaban sobre sus enemigos. También sus lugares de culto son muy parecidos en Fenicia y en Atenas. En los dos había un olivo, a cuyo tronco se enrolla una serpiente, tanto en Tiro como en la Acrópolis de Atenas ${ }^{69}$.

La Atenea Nike, adorada en Tiro, sin duda derivada de Anat y hay que hacer hincapié en que, en las monedas de esta villa, ella está simbolizada por una gran lechuza que tiene bajo sus alas los cetros de Osiris y de los faraones. Era la protectora de los Lágidas ${ }^{70}$.

Otra divinidad oriental relacionada con la serpiente, como ya dijimos, era Anat-Ashtart. La diosa Anat, hija de El, en Ras Sahmra (Ugarit), es llamada en los textos "la virgen Anat». Du Mesnil du Buisson ${ }^{71}$ la identifica cono la Atenea griega. En el templo de Beisan, Anat estaba simbolizada por numerosas serpientes ${ }^{72}$.

A menudo, la diosa Ashtart es escoltada por animales-atributo, entre ellos peces, escorpiones, palomas, serpientes o perros. Ello ha hecho que

chen Königskultes", Sb. Berlin 28. 1938. págs. 307 y Ss, : ViSSER, E., Göter uns Kultes i ptolemaischen Alexandrien 1938: Nilson. M. P., Gesch. d. Griech. Rel. 2. II; Fraser. P. M., Ptolemaic Alexandria 1972, cit. por Goukowsky. P.. Essai sur les origines du mythe d'Alexandre (336-270 av.J.C.: Les origines politiques. Nancy 1978. pag. 331. El Agatodaimon, el egipcio Knepp. era adorado como patrón de Alejandria. Nock. A. D., Conversion 1933, pág. 40. En las monedas de Neron del Egipto romano aparece una larga serpiente y una inscripción. Así. Nerón proclama que él es el nuevo Agatodaimon. cfr. ZOEGA, Num. Aegypt. tav. II. 9 y XIl: LenORMANt. Trésor de numism. lconnogr. rom. pl. XVI, 2; SABATIEA, IConogr. imp. XI, 20; cfr. Gerhard, “Ueber Agathodaemon uns Bona Dea", Abhandl. der Berlin. Akademie 1847; ldem, Gesammelte Abhandl 1868, t. Il. pag. 21; Preller, Griechische Mythologie 1. pag. 482, 2." ed. En forma de Agatodaimon se representó también a Antinoo. el favorito de Adriano. según una estatua descubierta en la villa Adriana. conservada en el Museo de Berlin. Sobre este culto cfr. OrR, D. G.. "Roman Domestic Religion of the Househol Shrines". ANRW 17.2, 1978, pags. 1592-1603: HARMON. D. P.. "The Family Festivals of Rome". ANRW 17.2, 1978. pags. 1593-1603 para las serpientes en los cultos familiares romanos

Cook, op. cit., III. partel pags. 749-763, tigs. 539-540. Para Tiro. véase Nonno. Dionysiacas, canto XL, trad. Marcellus, V. pág. 150.

Du MESNIL. Etudes sur les dieux pheniciens. Paris 1973. pág. 136.

Idem. págs. 48-53.

DU MESNIL, Etudes, pag. 136: VINCENT, L. H. "Les fouilles americaines de Beisan", en Revue Biblique XXXVII. 1928, págs. 123.138; Idem. "Le Ba al cannaneen de Beisan et sa paredre". Revue Biblique XXXVII. 1928. pags. $506-543$ 
se la confundiese con la Artemis cazadora, a la que Homero llama Potnia Theron o "Señora de los animales". Esto es, para Du Mesnil du Buisson un contrasentido iconográfico que se perpetúa hasta nuestros días ${ }^{73}$.

\section{c) Dioniso}

El culto místico de Dioniso quizá a partir de la reforma religiosa de Epiménides, tuvo una profunda conexión con los misterios eleusinos, asociándose a Deméter y a su hija Core o Perséfone, a la que se unía como hermano y esposo. Representado Dioniso como un joven varonil, a veces barbado (quizás por influencia de Heracles), era considerado un dios infernal, ctónico, al que se confundía con Hades, pero también recibía una clara influencia del Sabazio frigio, cuyo culto tenía carácter orgiástico, asimilado con frecuencia en el mundo griego a Dioniso ${ }^{74}$.

Según la leyenda, Zeus pasaba por haberse unido a Perséfone en forma de serpiente para engendrar a Sabazio y la serpiente era el animal sagrado de este dios y símbolo esencial de los misterios dionisiacos. La serpiente, además, estaba unida a la historia de Dioniso desde sus mismos orígenes. Recordemos que en la leyenda griega, su madre, Semele, era hija de Cadmo y Harmonia, metamorfoseados en serpientes ${ }^{75}$. Y que muerta Semele, Zeus salvó al feto cosiéndolo en su propio muslo hasta que llegase el momento de su nacimiento, tras el cual "le coronó con coronas de serpientes". Desde entonces, las Ménades, nodrizas de animales salvajes, se ciñen tal presa en sus cabellos trenzados ${ }^{76}$.

Y según una versión del destino de Dioniso, propagada especialmente por los órficos, cuya autenticidad ha sido defendida por Dods, los Titanes tomaron al dios recién nacido por orden de la celosa Hera, esposa de Zeus y trataron de destruirle, transformándolo entre otros animales, en serpiente, y tras ser despedazado y salir de su sangre una granada (también el fruto de Tammuz-Adonis-Rimnón) fue resucitado por su abuela Rhea. En los viajes de Dioniso, cuando éste viajaba en el barco de unos marineros tirrenos $"$ éstos quisieron venderle como esclavo, pero entre

Du MESNIL, op. cit., pàg 218

Sobre Sabazio cfr. JONHSON. S. E., en ANRW II, 17.3, págs. 1583-1613 y en las págs. 1316 1317 del mismo tomo con la última bibliografía sobre este dios hasta el año de la publicación

Euripides. Bac. vv. 1330-1339 y 1354-1362; Apolodofo III, 5, 4; Ovidio. Met. IV. 563-603 Hro. Fab. 6. Sobre Cadmo y Harmonia cfr. Rocchl. M. Kadmos e Harmonia, un matrimonio problematico. Roma, “L'Erma” di Bretschneider. 1989. págs. 118, 131 y ss

EuripIDEs, Bac. 100-101

Aunque según Tucidides. IV. 109. eran de Lemnos y una parte del Atica 
otros prodigios que el dios realizó para impedirlo, los remos se convirtieron en serpientes.

\section{d) La cista mística}

La cista mística representada en los cistóforos servía para conservar los objetos sagrados y misteriosos utilizados en las ceremonias de iniciación del culto dionisíaco (fig. 8). Precisamente, las más antiguas representaciones que tenemos de esta cista dionísiaca se encuentra en los cistóforos de plata a los que venimos aludiendo, siendo descrita bellamente en una obra de Catulo ${ }^{78}$. En las monedas se ve la cista, a menudo abierta, de la que escapa una serpiente. Recordemos entre otros los cistóforos de Amiso, en el Ponto, en los que se representa la cista mística cubierta con piel de pantera y un tirso, emitido durante el reinado de Mitrídates Eupator (120-63 a.C.) y una cabeza de Dioniso joven en el anverso. También la llevan los tetradracmas de Pérgamo de 165-195 g de peso, acuñados entre el 200-133 a.C., cuyos tipos repitieron gran número de ciudades, como arriba dijimos ${ }^{79}$.

En época romana, los cistóforos se mantuvieron durante algunos años. Así, los de Magnesia, en Jonia, que emiten también el tipo de cista mística y serpiente y los de Sidón, en Fenicia ${ }^{80}$, continuando la utilización de un tipo que era familiar a los nuevos ciudadanos romanos. $Y$ aunque es difícil averiguar hasta qué punto la serpiente es representada en los cistóforos por si misma, como genio protector o como simbolo benefactor que acompañaba a las divinidades protectoras de las ciudades en que se acuñaban, su presencia hace evidente su importancia a nivel internacional, hasta el punto de ser un tipo constante en los reversos, mientras las diversas divinidades aparecen en las diferentes ciudades, pero no de forma continuada.

El significado religioso de la serpiente en las monedas «paganas» queda, pues, patente, en las estampaciones monetarias de sus caras. Además de la representación de la citada cista mística y la serpiente, ciertas emisiones de cistóforos representaban en sus anversos a diferentes divinidades como hemos visto: la cabeza del joven Dioniso en Amiso y Sidón. en otras monedas, como las emitidas en Lidia, aparece la cabeza de

CAT.. LXIV

- PLANT, R., Greek coins types and their identification. Londres 1979, nums. 2083. 2084 2085, 2086. pág. 116: "Jars and vases". Basquet, box, etc.

PLANT op. cit. pag. 98. 


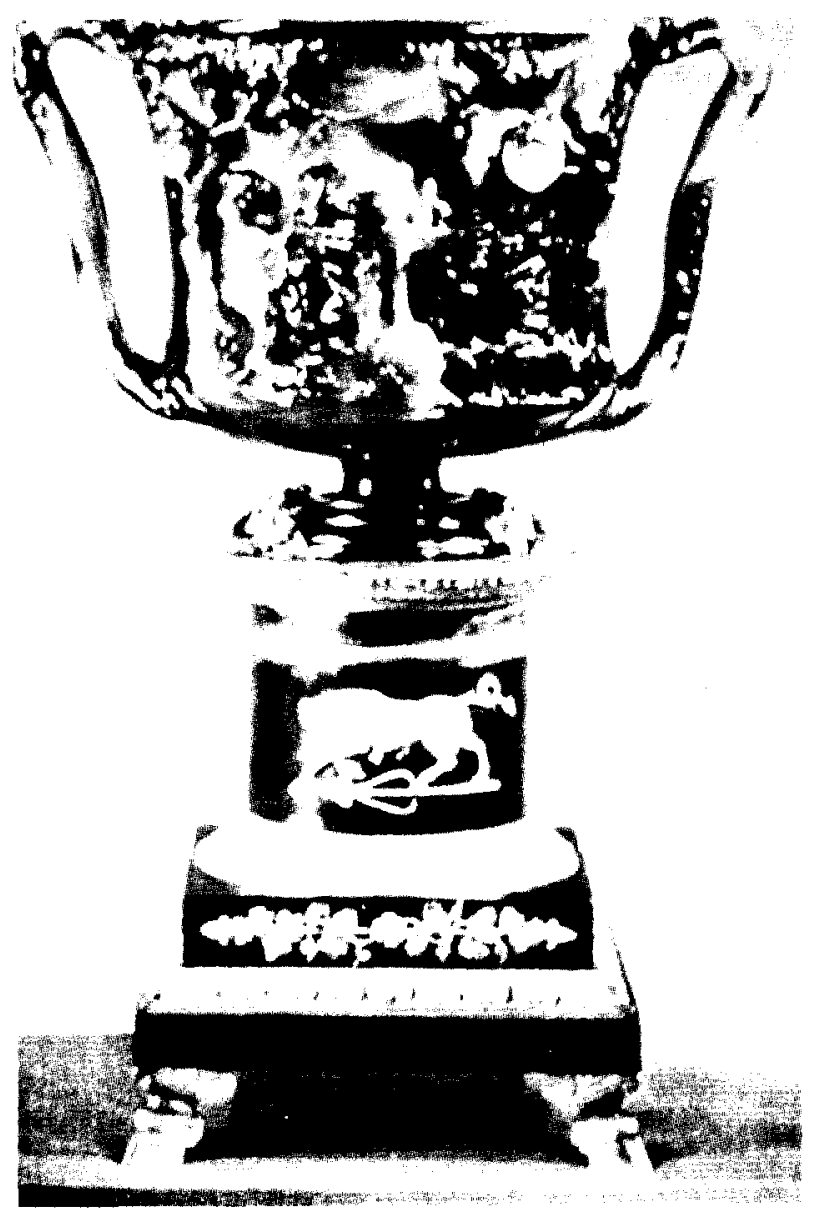

Fig. 8. Vaso de sardonice conocido como "Copa de los Ptolomeos". Biblioteca Nacional, Paris. Probablemente procede de Asia Menor. En medio de gran cantidad de objetos preparados para celebrar la fiesta de Baco, como máscaras y vasos, aparece la cista mistica, de la que escapa una serpiente.

Deméter, rodeada de sus atributos o con símbolos o atributos de otras divinidades.

A medio camino entre la significación religiosa y económica de los cistóforos debemos tener presente, una vez más, que las monedas fueron puestas bajo la advocación de determinadas divinidades, cuya devoción y prestigio llenaba todo el área del Egeo. Sus templos fueron, en múltiples ocasiones, garantes de los depósitos bancarios, cuyas operaciones eco- 
nómicas jugaron un papel importante en la economía de la Antigüedad ". Según Bogaert ", veinticuatro templos griegos se ocuparon de operaciones bancarias y solamente de tres: Delfos, Efeso y Priene, se atestiguan depósitos y préstamos. Hay más precisión para el templo de Artemis en Efeso, ya que Artemidoro de Efeso (siglo lla.C.) y Dion Crisóstomo (40-112 d.C.) afirman que los depósitos permanecian intactos en las cámaras acorazadas del Artemisión, y que la ciudad no los tocaba ${ }^{83}$. Cuando Atalo II dejó su reino y herencia a Roma, los cistóforos cambiaron. Y en el curso del tiempo, de monedas ciudadanas, pasaron a ser la moneda oficial y local de curso legal en la nueva provincia de Asia, como arriba dijimos.

Hacia mediados del siglo เ a.C. se introdujeron modificaciones en la fabricación de los cistóforos. Se escribe en latín el nombre de los procónsules de las dos provincias donde se acuñaban las monedas, de la provincia de Cilicia en la que estaba comprendida Frigia y de la provincia de Asia, que comprendia Misia, Jonia y Lidia. Entre estos nombres de procónsules se encuentra el de M. T. Cicerón, que figura en los cistóforos de Apamea y Laodicea (fig. 9).

En el cistóforo de Laodicea figura con el título de imperator que se hizo atribuir tras una pequeña victoria en una escaramuza con sus soldados ${ }^{84}$.

Bogaert, R. Les origines antiques de la banque de dêpot. Une mise au point d'une es quisse des operations de la banque en Mesopotamie. Leiden 1966, págs. 43-63; Idem. Banque et baquiers dans les cités grecques, núms. 26, 3, pág. 130. Sobre los banqueros sagrados ctr. núm. 3, pág. 130, como hicieron los santuarios en la antigua Mesopotamia, también los templos griegos se ocuparon de operaciones bancarias y a menudo se les ha denominado «banqueros sagrados". Entre los más ilustres se encuentra el Artemisión de Efeso. La seguridad de sus depósitos era tal que muchos autores griegos desde Aristófanes en el siglo v a Elio Arístides en el siglo ॥ d.C hacen un elogio de ella. También los templos de Hera en Samos, Apolo en Delfos, Atenea Lindas en Rodas. Atenea Aléa en Tegea y otros tenian cámaras de depósito y cajas fuertes a disposición de sus fieles. Otros santuarios, como el templo de Apolo en Delos. han prestado sus fondos disponibles a Estados y a particulares. Las mismas operaciones se atestiguan para el templo de Zeus en Olimpia, de Artemis en Sardes, de Atenea en Priene e Ilión, de Apolo, Atenea y Artemis en Halicarnaso y también otros santuarios menores, como los de Mirrinonte en el Atica, el de Distos, cerca de Eretría, el de Apolo en Cartaia, en la isla de Céos, etc., han hecho fructiferar sus fondos prestándolos a interés. También algunos templos emitieron monedas, acuñando sus depósitos de plata, que llevan su efigie o su leyenda. Por ejemplo, los de Olimpia y Heraia, el de Apolo de Didime, en Mileto y las emisiones de la Anfictionia de Delfos.

"3. Bogaert, Les origines, cit. pág. 131, también Vazouez Hoys, A. M. ": "El papel económico del templo de Heracles Melkart en Cádiz", en Studis Economics. Palma de Mallorca, en prensa

${ }^{83}$ Estrabon, XIV, I, 22; Dion CaIsostomo, XXXI, 54-55.

${ }^{4}$ CICERON, Ad fam. II, 10: V. 20; Ad Att. II, 8 y 16; XI, 1 


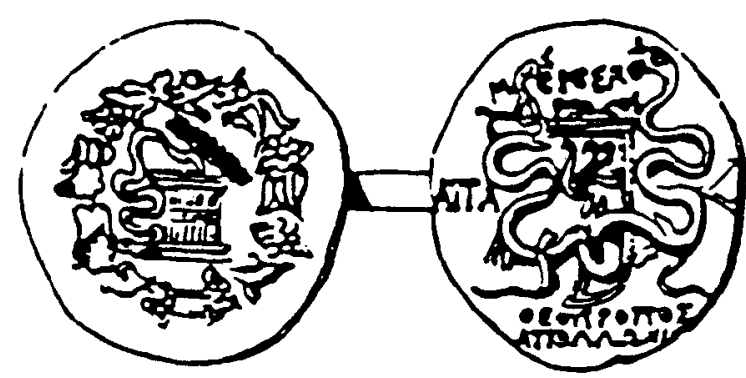

Fig. 9. Cistoforo proconsular de Cicerón, acuñado en Apamea

Además, sobre los cistóforos proconsulares de la provincia de Asia, en lugar del arco en su estuche, gorytos, las serpientes rodean ahora entre sus pliegues un símbolo que cambia cada año ${ }^{85}$ : un águila legionaria sola, un trípode sobre el que se ve un águila legionaria, un edículo períptero, etc. Tras estos cambios, se llega a los tetradracmas que tienen en el anverso, en la corona de hiedra, la cabeza de Marco Antonio en lugar de la cista mística y en el reverso, entre dos serpientes, la cabeza de Octavia (fig. 10). O bien en el anverso las dos cabezas unidas de Antonio y Octavia y en el reverso las dos serpientes rodeando la cista mística y sobre ella una imagen de Baco-Dioniso.

Tras la derrota de Marco Antonio, Octavio hizo acuñar dos monedas:

- Un trióbolo o hemidracma del sistema de los cistóforos que lleva en el anverso su cabeza y en el reverso una victoria de pie sobre la cista que rodean las dos serpientes, con la leyenda ASIA RECEPTA.

- Un tetradracma que lleva en el anverso la cabeza de Octavio con la leyenda IMP(erator) CAESAR DIVI F(ilius) CO(nsul) VI LIBERTATIS $P$ (opuli) $R$ (omani) VINDEX y en el reverso una corona de olivo, una figura de la Paz, con un caduceo y tras ella la cista abierta de la que escapa una serpiente (fig. 11).

Las dos monedas citadas anteriormente son las últimas, para Lenormant, a las que se puede designar con el nombre de cistóforos. Después de la organización completa del poder imperial, la provincia de Asia no perdió de repente el derecho a tener su propia moneda de plata. Hasta el reinado de Adriano se continuó acunanando tetradracmas pertenecientes al mismo sistema de peso que los cistóforos. Pero la cista, que era ya 


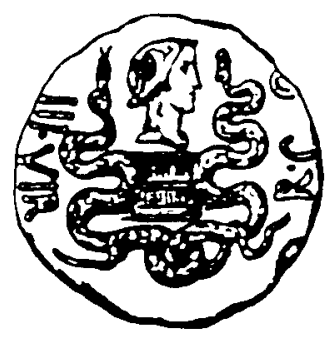

Fig. 10. Cistóforo de ... Antonio Octavia Reverso.

algo casi secundario en las monedas de Antonio y Octavia, desapareció completamente de los tetradracmas imperiales, equivalentes siempre a tres denarios. Estas monedas, salvo en el peso y su naturaleza, ya nada tenían de griegas y eran completamente parecidas a las acuñadas en Roma. Las leyendas eran completamente latinas: en el anverso se ve la cabeza del Princeps reinante y en el reverso tipos varios, pero siempre subordinados a la efigie de éste ${ }^{86}$.

La serie se interrumpió algún tiempo durante los gobiernos de Nerón y Vespasiano, que intentaron sustituir por estas piezas los dracmas y didracmas, llevando la indicación de su valor y talladas sobre el patrón un poco diferente que se usaba en el taller provincial de Cesarea de Capadocia. Pero la tentativa no dio resultado y tras Vespasiano se volvió a fabricar los tetradracmas del antiguo patrón.

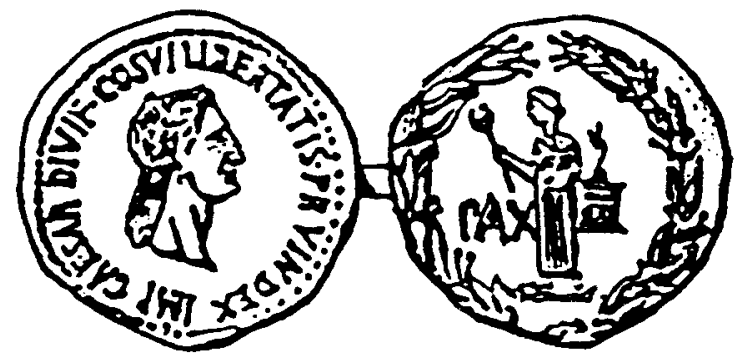

Fig. 11. Cistoforo de Octavio.

En época de Adriano se procedió a controlar los cistóforos que aún existian y circulaban en la provincia de Asia. Los que habian perdido

KLEINEA, F. S. y NOE, S. P.. "The Early Cistophoric Coinage", ANSNS 14 Nueva York 1977. 
mucho peso fueron retirados. Los que estaban usados pero cuyo peso era aún aceptable, se volvieron a marcar y siguieron en circulación. Después de Adriano ya no se acuñaron tetradracmas provinciales, pero la utilización de los antiguos continuó en el interior de la provincia al menos hasta la gran crisis del siglo $1{ }^{87}$.

\section{LA SERPIENTE EN LAS MONEDAS BAJOIMPERIALES ROMANAS}

A partir del siglo IV d.C., un hecho fundamental tiene lugar en el Imperio romano: la conversión oficial al cristianismo. Este hecho, capital para la historia de las religiones, aportará nuevos datos sobre la serpiente y serán de nuevo las monedas las que nos informen de su significación. Es decir, de nuevo las monedas servirán de propaganda de unas ideas religiosas, en este caso la serpiente será considerada como "el enemigo" de la religión triunfante, junto con otro animal que a veces también hemos encontrado unido a la figura de la serpiente: el león.

El simbolismo del león y la serpiente aparece por primera vez en las monedas romanas en los solidi acuñados por los emperadores de Occidente, Honorio, Valentiniano Ill y Petronio Máximo, de cuatro emisiones que se fechan en los años $421,425,453$ y $455^{88}$, aunque la serpiente aparece sólo en los de Valentiniano III.

Anteriormente, desde la época republicana hasta fines del siglo IV d.C., en los reversos de las monedas, los generales y luego los emperadores vencedores se representaban en forma de caballeros venciendo a un enemigo, generalmente un bárbaro, en el curso de alguna batalla, en los siglos II y III, de una forma convencional que había inspirado las representaciones del conocido “cavalier à l'anguipède»: Júpiter como dios solar venciendo a un gigante de cuerpo serpentiforme, cuyas estatuas se colocaban a menudo sobre columnas, de las que se han levantado alrededor de ciento cincuenta en las provincias de la Galia septentrional o Germania ${ }^{89}$.

De esta forma se representaba también a algunos emperadores, como

KLEINER. F. S. "The Late Cistophori of Apameia". Greek Numismatic and Archaeology, cit págs. 119-130, pl. 12-14: REGLING K. "Ein Kistophorennschatz aus der Provinz Brussas". Frank furter Münzzeitung 34. Francfort 1932. págs. 506-510.

Demougeot. E.. "La syrnbolique du lion et du serpent sur les solid des empereurs d'OCcident de la prémiere moitié du Ve siecle", Revue Numismatique, Ve. Serie. 1986, t. XXVIII. t. XXVIII. pags 95.118 y pl. VII.

DE VRIEs. J. La religion des Celtes. Paris 1963. págs. 39.42 
a Trajano venciendo a los dacios, en una moneda de los años 103-111 o a Adriano venciendo a una amazona.

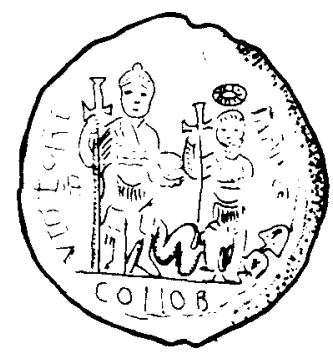

Fig. 12. Valentiniano III y la serpiente con cabeza humana. Demougeot, pl. VII, 6.

Pero a partir del siglo IV, los emperadores cambiaron la simbología, representando a sus enemigos, además de por el citado león, por la serpiente con cabeza humana, animales que forman parte de la simbología cristiana de origen necesariamente bíblico, en la que estos animales representan a los enemigos de Dios y del pueblo de Dios (figs. 12-13).

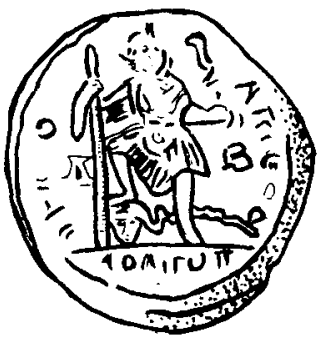

Fig. 13. Severo lll y la serpiente con cabeza humana. COURCELLE, fig. 3.

El carácter peyorativo que la serpiente toma en el cristianismo puede derivar de la imagen del Antiguo Testamento, donde de ser un simbolo de salvación, representado por la vara de Moisés, es tal vez, a su vez. uno de los más fuertes dioses o diosas cananeos, adversarios del naciente yahvismo exclusivista. Además era el gran dragón primordial que Israel recibe de la herencia ugaritica y de las innumerables diosas y diosesserpiente del panteón egipcio ${ }^{30}$.

VAzOUE 2 HOYS. A. M. "Aquella que ama el silencio: Sobre la serpiente en los antiguos cultos egipcios". Espacio. Tiempo y Forma. serie II, núm. 4. pág. 37-72: Idem. "Dioses y diosas del Proximo Oriente y las serpientes" cit. en prensa. 
Los autores cristianos, de Tertuliano a Casiodoro, simbolizaron al adversario de Yahvé, diabolus, por la doble forma de león o de serpiente ${ }^{91}$ sobre todo San Agustín, que interpreta así el Salmo 91,13:

«Sobre el león y el áspid caminarás y pisarás al leoncillo y al dragón.»

pero teniendo sobre todo al dragón como el gran enemigo del cristianismo, tanto en el siglo III como en el IV ${ }^{92}$ (fig. 14), algo que ya sucedía en época de Constantino, pues este Emperador celebró sus victorias danubianas entre 326 y 330 , emitiendo monedas en las que figura la serpiente, simbolo del Danubio, Ister, liberado.

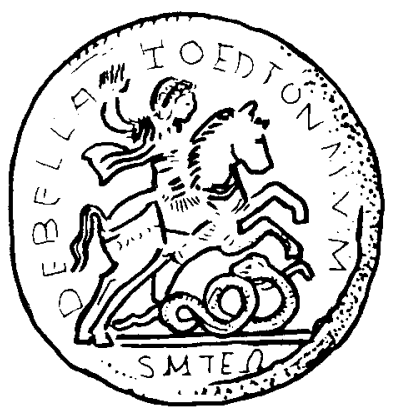

Fig. 14. Honorio en el reverso de los solidi emitidos después del 8 de agosto del 411 d.C., venciendo a un león. DEMOUGEOT, pl. VII, 5

Esta misma serpiente, “el enemigo del género humano», está representada, según Eusebio, en la Vita Constantinii, en una pintura del vestíbulo del palacio de Constantinopla, simbolizando a Licinio. El mismo simbolo del Emperador a caballo, venciendo a la serpiente, es utilizado por Constantino II en un medallón de oro emitido poco después de su victoria sobre el usurpador Magnencio en 353, representando según Demougeot, a los enemigos bárbaros del Imperio como la serpiente Ister de los nummi del 327 acuñados por Constantino.

Pero ya después del 395 , en el siglo $v$, cuando la ortodoxia simboliza a los herejes por la serpiente, el adversario de Dios, representante del mal espiritu, será el león, el que pasó a simbolizar a los enemigos pa-

Quacouarelli, A., "ll leone e il drago nella simbolica della eta patristica". Quaderni di Vetera Christianorum II. Bari 1975

DEMOUGEOT. op. cit. pág. 96 
cíficos del Imperio, pero este simbolismo se fue alterando por la multiplicación de estos enemigos. Y fue sobre todo en la parte occidental del Imperio donde los bárbaros invasores, los usurpadores o los rebeldes se convirtieron en enemigos tan peligrosos que fueron simbolizados por la serpiente, enemigo mucho más temible que el león ${ }^{93}$, mientras que más tarde, ya en el 411, pasó a simbolizar la herejía donatista, mal pérfido que corrompe el espíritu de los cristianos, pero asumiendo el papel de enemigo "escondido", "sutil», de la misma forma que el león sería el mal, por así decirlo, "noble», que ataca de frente abiertamente (fig. 15).

Para San Agustín, en cambio, la Iglesia ortodoxa no tiene más que un solo enemigo, con doble forma: el león, que representa las persecuciones exteriores de los emperadores paganos contra los cristianos y el dragón o la serpiente, que simboliza el falso cristianismo de los herejes que hacen renegar de Cristo a los cristianos, identificando esta serpiente, es decir, a la gran serpiente tannin, del Antiguo Testamento que había tentado a Eva, con los peores de los peligros que amenazaban a la Iglesia de Cristo.

Otros nuevos avatares sufrió el Imperio romano con los reinados legitimos y las usurpaciones de diversos emperadores durante los años siguientes. Bástenos recordar que Valentiniano ll celebró su advenimiento al trono haciendo acuñar en Roma solidi en cuyos reversos figura coronado por la mano de Dios, al lado de Teodosio ll. Ambos están de pie, con un globo terráqueo en la mano, cada uno armado con una lanza terminada en forma de cruz latina, y una serpiente con cabeza humana a sus pies, a la que lancea solamente Valentiniano III (fig. 12).

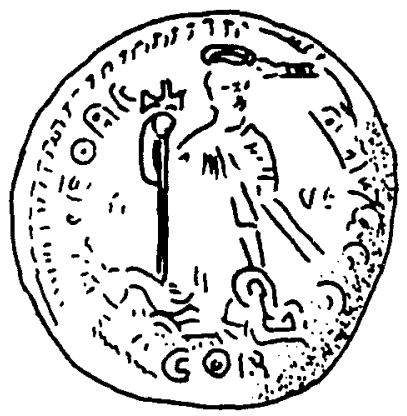

Fig. 15. Constancio ll sobre un medallon de oro, posterior al año 353. Leyenda: Debellator hostium, venciendo a la serpiente Ister. Demougeor, pl. VII. 3. 
Según Demougeot ${ }^{94}$, si Honorio, había simbolizado a los enemigos del Imperio romano por medio de la figura de un león (fig. 14), Valentiniano III en el 425 altero el simbolismo anterior, representando al usurpador Juan por una serpiente con cabeza humana, ya que ésta no se parece a la serpientedragón simbolo de los herejes según San Agustín ni a la gran serpiente que habia representado a los enemigos de los emperadores cristianos del siglo IV, en una época en la que la ortodoxia católica aún no era religión de Estado, por lo que los herejes no eran considerados aún como enemigos comunes del Estado y de la Iglesia.

Por otra parte, también en los tiempos de Honorio, la mayor parte de los usurpadores eran católicos y sólo Atalo se habia convertido al arrianismo cuando Alarico ie proclamó Augusto en noviembre del año 409.

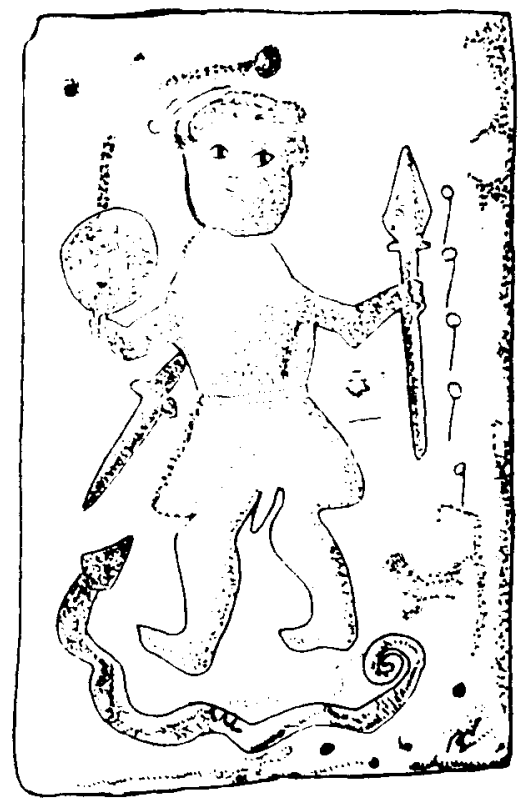

Fig. 16. Placa paleocristiana de terracota de Grésis (Comuna del Broc, Puy de Dôme). Vallet, F.-QueRre, G., "Authenticité de la plaque paléochrétienne de terrecuite dite de Grésin (Comune du Broc, Puy de Dôme)", Antiquités Nationales 1989, núm. 21, fig. 1. 
En cuanto al usurpador Juan, culpable de haber traicionado la ortodoxia, parece no haber profesado ninguna herejía.

Por esto fue, tal vez, por lo que no se le pudo representar por medio de una serpiente-draco, que simbolizaba la herejía y porque el usurpador de Ravena, a la manera de la serpiente diabólica que pervierte a la Iglesia. era un enemigo más peligroso para los emperadores ortodoxos que los bárbaros invasores vencidos por Honorio.

Por eso, éste representa a Juan como una serpiente con cabeza humana, es decir, un monstruo que, más que el "anguipède" que figuraba antiguamente el furor anónimo dominado por el "caballero divino", podía simbolizar el engaño pérfido de Satán encarnado en el usurpador alzado contra el Emperador coronado por Dios, un monstruo más peligroso aún y más terrible que la simple serpiente o el tremendo dragón biblico

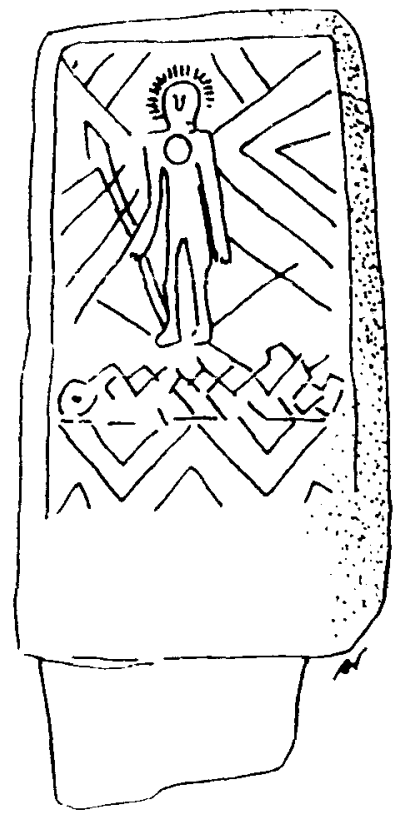

Fig. 17. Estela de Niederdollendort. Idem, fig. 2.

Más tarde, Petronio Máximo, tanto por aparecer como digno sucesor de Valentiniano III como para llamar la atención de Marciano, que aún no le había reconocido como Emperador, hizo acuñar solidi en los que figuraba la misma serpiente que en los solidi de Valentiniano III, emitidos 
en 425 y 453 . En este caso, la serpiente con cabeza humana simbolizaba a Genserico, rey bárbaro usurpador y herético al que, como en 425 , el Emperador de Occidente no podía vencer sin el apoyo del Emperador de Oriente, anticipada la victoria para la leyenda impresa en la moneda: Vic toria Augg.

Victoria que no se cumplió, ya que Genserico entró en Roma, a la que sometió a pillaje, tomando como prisionera incluso a la Emperatriz Licinia Eudoxia y a sus dos hijas, lo que permitió al rey vándalo casar poco después a su hijo Humerico con la princesa Eudocia.

Pero este simbolismo de la serpiente con cabeza humana solamente fue utilizado, según Demougeot, por los emperadores de Occidente de origen occidental, no por los de origen oriental, tal vez porque Genserico era arriano y se buscó para simbolizarle una variante de la serpientedragón que anteriormente representaba a los herejes.

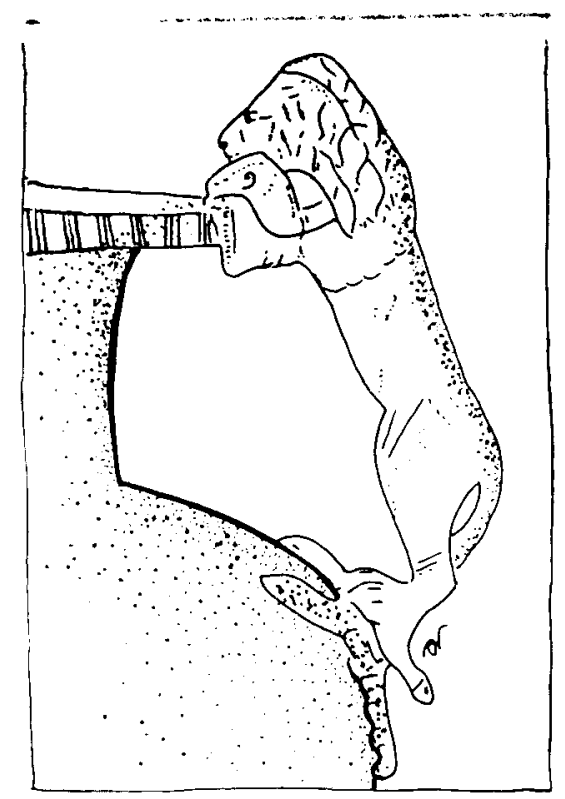

Fig. 18. Crátera de bronce cuya asa está formada por un leon y cuatro serpientes. NEUISCH, B., TAS NIMPHAS EMI HIARON zum unterirdischen heiligtum von Paestum. Carl Winter Universit. Heidelberg 1957, fig. 17. Siglo via.C.

Después de la muerte de Teodosio II, en julio del año 450, Valentiniano III figura en el reverso de los solidi que se fechan entre 450-455 aplastando 
la serpiente de cabeza humana (fig. 12) armado de una alta lanza cruciforme, celebrando una victoria que para Demougeot sólo puede ser la derrota de Atila, ocurrida en el curso del invierno del año 453.

Tal vez, por eso, un nuevo Emperador de Occidente, Mayoriano, sucesor de Marciano, en el año 457, que luchó contra Genserico en una gran expedición en el año 460, hizo acuñar nuevos solidi en los que nuevamente figuraba la serpiente con cabeza humana.

Curiosamente, Livio Severo, proclamado Augusto en noviembre del año 461 por el generalisimo suevo arriano. Ricimero, acuñó solidi en cuyo reverso figura también la serpiente con cabeza humana ${ }^{95}$.

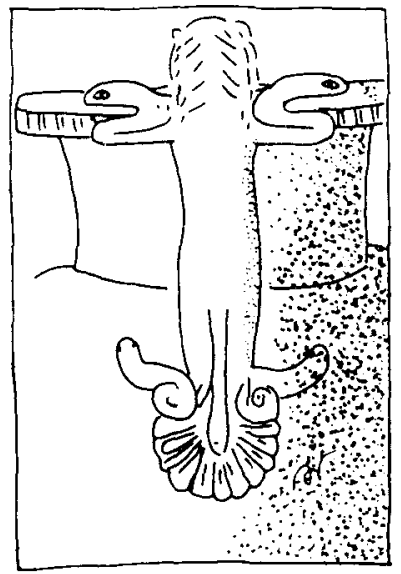

Fig. 19. La figura anterior vista por detras.

En fin, puesto que, como ya dijimos, un trabajo exhaustivo excede las posibilidades de este trabajo, nos detendremos aquí, recordando que la serpiente fue para los emperadores cristianos señalados un símbolo del mal. Pero del mal espiritual, mientras que el mal material fue encarnado por la figura del león.

De la serpiente babilónica buena y protectora, la buena diosa de Beisan

9. LAFaurie. J., "A propos de deux monnaies d'or de Sévère li trouvées en Anjou". BSFN 1982, págs. 194-196, LORiOT. X., "Deux solidi de Livius Severe découverts dans le Sud de I'Anglaterre". BSFN 1984, pags. 554-555. También sobre este tema CouRCEL.t. P., "Le serpent à face humaine dans la numismatique impèriale du Ve. siècle", Mélanges d'Archeologie et d'His. torie offerts à Andre Piganiol. Paris 1966, págs. 343-353 
- la Señora del Hogar minoica al dragón marino, símbolo de lo indeterminado o lo preformal de los milenios anteriores a nuestra Era a la serpiente con cabeza humana de las monedas bajoimperiales ha pasado mucho tiempo. Tanto que, a menudo, es difícil reconocer su antiguo valor como símbolo positivo y su carácter de imagen de los poderes de las divinidades protectoras y benéficas, subsistiendo su papel reducido a unos valores negativos que perviven hasta la actualidad, quedando la imagen de la serpiente como un arquetipo negativo anclado en el subconsciente humano ${ }^{96}$.

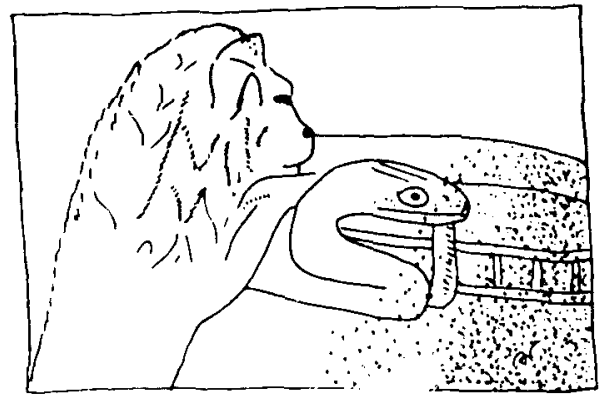

Fig. 20. Detalle de la figura anterior.

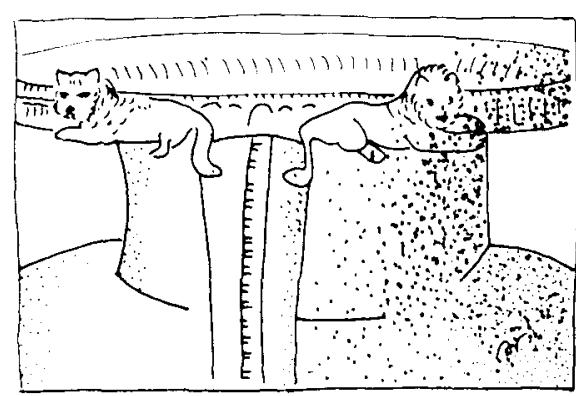

Fig. 21. Parte superior de otra cratera de Paestum, con serpientes y leones. NEUTSCH, fig. 12

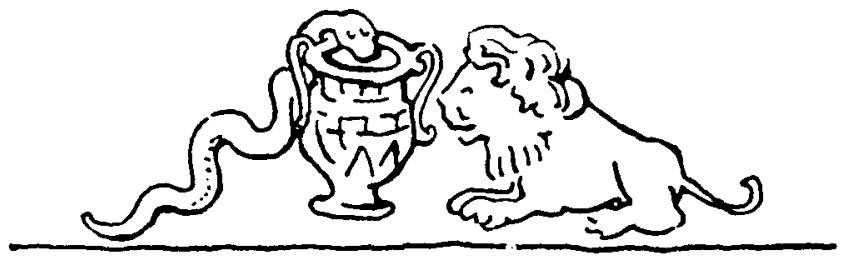

Fig. 22. Grupo trinario mitraico. Serpiente-leon-cratera. WiLl, op. cit., pag. 405. fig. 72

Evidentemente han pasado muchos siglos desde que leones y serpientes eran representados juntos en las cráteras de Paestum (figs. 1720) o constituían uno de los símbolos preferidos en la iconografía mitraica (figs. 22 y 23).

"Chorsy, M.. "L'archetype des trols S: Satan. Serpent. Scorpion", Etudes Carmelitaines 1948, pags $442-451$ 


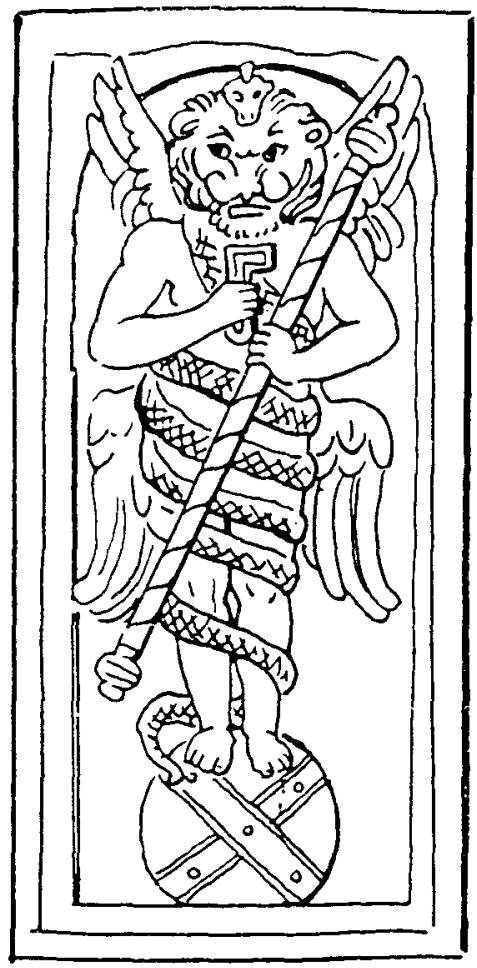

Fig. 23. Kronos-Aion mitraico. WILL, E., Le réliet cultuel gréco-romain. Paris 1955 , pág. 187 , fig. 30

Este cambio de significación lo hemos apreciado sobre todo en las monedas, que nos han servido, en momentos puntuales, para comprender y aclarar el significado de la serpiente representada en sus caras, siempre como reflejo de las ideas de la época en que fueron acuñadas. Y sirviendo de vehículo para la propagación de las mismas.

\section{RESUMEN}

Presentamos en este trabajo un breve estudio sobre la evolución en el mundo antiguo del significado de la figura de la serpiente, además de su particular presencia en algunas monedas antiguas.

Mientras que en las griegas la serpiente es un genio benéfico y po- 


\section{SUMMARY}

We present here a brief study about the evolution of the figure of the snake and its significance throughout the times, besides its particular presence in some antique coins.

While in the greek ones the snake is a beneficent genius, in those of the Roman empire it will represent the enemies of political and religious powers.

In memory of the recently deceased professor Maria Gimbutas. 